This is the peer reviewed version of the following article: Budziński, W. , Campbell, D. , Czajkowski, M. , Demšar, U. and Hanley, N. (2018), Using Geographically Weighted Choice Models to Account for the Spatial Heterogeneity of Preferences. J Agric Econ, 69: 606-626, which has been published in final form at https://doi.org/10.1111/1477-9552.12260. This article may be used for noncommercial purposes in accordance With Wiley Terms and Conditions for self-archiving.

\title{
Using geographically weighted choice models to account for the spatial heterogeneity of preferences
}

W Budziński, University of Warsaw

D Campbell, University of Stirling

M Czajkowski, University of Warsaw

U Demšar, University of St Andrews

N Hanley, University of St Andrews

\section{Accepted for publication in Journal of Agricultural Economics published by Wiley-Blackwell.}

\section{Abstract}

In this paper, we investigate the prospects of using geographically weighted choice models for modelling of spatially clustered preferences. We argue that this is a useful way of generating highlydetailed spatial maps of willingness to pay for environmental conservation, given the costs of collecting data. The data used in this study comes from a discrete choice experiment survey regarding public preferences for the implementation of a new country-wide forest management and protection program in Poland. We combine it with high-resolution spatial data related to local forest characteristics. Using locally estimated discrete choice models we obtain location-specific estimates of willingness to pay (WTP). Variation in these estimates is explained by characteristics of the forests in their place of residence. The results are compared with those obtained from a more typical, two stage procedure which uses Bayesian posterior means of the mixed logit model random parameters to calculate location-specific estimates of WTP. We find that there are indeed strong spatial patterns to the benefits of changes in management to national forests. People living in areas with more species-rich forests and those living nearer to higher areas of mixed forests have significantly different WTP values than those living in other locations. This kind of information enables a better distributional analysis of the gains and losses from changes to natural resource management, and better targeting of investments in forest quality. 
1 Keywords: discrete choice experiment, contingent valuation, willingness to pay, spatial 2 heterogeneity of preferences, forest management, passive protection, litter, tourist infrastructure,

3 mixed logit, geographically weighted model, weighted maximum likelihood, local maximum 4 likelihood

5 JEL classification: Q23, Q28, 138, Q51, Q57, Q58

\section{Highlights:}

7 - A discrete choice experiment related to forest management and protection in Poland is $8 \quad$ conducted

9 - The spatial heterogeneity of respondents' preferences and willingness to pay is investigated

10 - The possibility to use the geographically weighted multinomial choice model is explored and 11 compared with the typical 2-step approach

12 - The analysis highlights advantages and disadvantages of the two approaches 
2 Preferences for environmental goods are likely to display spatial patterns such as clustering. One

3 reason for this is that since there are differences in the spatial configuration of these goods.

4 Peoples' preferences can be expected to adapt to their local environments (Nielsen, Olsen and

5 Lundhede, 2007) and to the availability of substitutes (Munro and Hanley, 1999). So, for instance,

6 living in an area with high levels of forest cover may induce people to value the conservation of

7 forests more highly than those who live in less-forested landscapes. Another line of reasoning

8 concerns residential sorting: people's preferences for environmental goods partly determine

9 where they choose to live, so that measures of preferences tend to be correlated with measures

10 of environmental quality or with distance to environmental amenities (Timmins and Murdock,

11 2007; Timmins and Schlenker, 2009; Baerenklau et al., 2010). These two views on the reasons why

12 spatial patterns are present in values and preferences for the environment can be thought of as

13 different perspectives in the directional drivers which link values with environmental features.

14 From the policy and management perspective, enhancing our ability to produce detailed spatial 15 maps of willingness to pay is important. For instance, national forest planners might want to target 16 forest regeneration or investments in forest recreational resources in areas where the benefits of

17 such actions would be highest. National water quality managers might, similarly, be interested in

18 targeting costly actions to reduce pollution in a way which reflects the variation in values across a

19 population. The application of benefit-cost thinking to spatial planning indeed requires such highly

20 disaggregated benefits information. However, given the costs of undertaking a large number of

21 original Willingness to Pay surveys at multiple sites, there is an interest in new methods which

22 allows spatial maps of values to be generated in a data-efficient manner as a form of benefits

23 transfer.

24 Accounting for spatial dependencies is insightful for various reasons, including in the aggregation 25 of benefits, as illustrated by Bateman et al. (2006) in terms of identifying what "relevant 26 population" of beneficiaries from a resource quality change should be considered. One of the most

27 commonly encountered examples is the distance decay relationship (e.g., Jørgensen et al., 2013).

28 However, distance is not the only spatial factor which should be considered. For example, 
1 availability of site substitutes can vary across space, and it is likely to influence willingness to pay

2 considerably. However, because in most applied cases researchers are not able to account for all

3 possible spatial factors, there is a need for a method, which would allow to take into account

4 different spatial dimensions of preferences, with possible nonlinear relationships and clusters.

5 Recent developments in Geographical Information Science (GIScience) allow the researcher to 6 obtain rich datasets containing detailed information about the spatial configuration of 7 environmental goods and indeed in the socio-economic characteristics of households, and then

8 use these to investigate spatial patterns in stated and revealed preferences for such environmental 9 goods. In this paper, we employ a method which, while widely used in other areas of social science, 10 remains relatively unknown in agricultural and resource economics: Geographically Weighted 11 Regression (GWR) as proposed by Fotheringham, Charlton and Brunsdon (1998). Specifically, we 12 apply geographical weighting to choice models to investigate the spatial relationship of willingness 13 to pay for landscape characteristics, using the example of national forest management in Poland.

14 The rationale of this statistical approach is that, if spatial clusters of preferences do exist, a locally15 weighted maximum likelihood method can be used to derive location-specific estimates.

16 Estimation of such models can provide us with insight regarding multiple possible spatial patterns 17 of preferences and welfare measures. This is a semi-parametric approach in that no a priori 18 assumptions about the spatial distribution of preferences are made.

19 Economists have used a number of ways for spatial value interpolation and mapping (Johnston and 20 Ramachandran, 2014). This includes the use of micro-simulation methods such as combinatorial 21 optimization, as used by Hynes, Hanley and O'Donoghue (2010) for spatial aggregation on 22 contingent valuation survey data and a "two stage" analysis, which involves estimating a Mixed

23 Logit (MXL) model to derive location-specific WTP values, and using these WTP estimates as 24 dependent variables in a GIS-based spatial regression (see for example Campbell, Hutchinson and 25 Scarpa (2009) and Czajkowski et al. (forthcoming-a)). The relevant question is thus whether the 26 geographical weighting approach offers advantages relative to existing methods. We therefore 27 compare the results obtained using geographically weighted multinomial logit (GWMNL) model 28 with the latter, "two stage" approach. This comparison reveals that although there are similarities 
1 in the spatial distributions of preferences identified using the two methods, the results differ in

2 several important ways.

\section{Geographically weighted models in the literature}

5 Geographically weighted models belong to the general class of "locally estimated" models. These

6 recognize that the relationships between analyzed variables may be highly nonlinear which are

7 therefore difficult to represent parametrically. Early examples of such models consist of use of

8 spline functions (Wahba, 1990), LOWESS regression (Cleveland, 1979) and kernel regressions (Fan

9 and Gijbels, 1996). The geographically weighted approach differs, because it recognizes nonlinear

10 relationships with respect to spatial dimensions.

11 Early applications of geographically weighted models were based solely on linear local models.

12 They were used for analysis of morbidity (Fotheringham, Charlton and Brunsdon, 1998), house

13 price data (Brunsdon, Fotheringham and Charlton, 1999), economic growth (LeSage, 1999), school

14 performance (Fotheringham, Charlton and Brunsdon, 2001) and urban temperatures (Páez, Uchida

15 and Miyamoto, 2002). In the context of non-market valuation, this approach has been used with

16 hedonic price models of house prices in Cho, Poudyal and Roberts (2008) or Saphores and Li (2012).

17 Local likelihood models were introduced by Fan, Heckman and Wand (1995) and Fan, Farmen and

18 Gijbels (1998). These use weighted maximum likelihood estimators for inference. Applications of

19 these techniques in discrete choice models are very limited, and were undertaken mostly in

20 context of transportation. Locally estimated models are used either to recover WTP distribution

21 non parametrically such as in Fosgerau (2007), Börjesson, Fosgerau and Algers (2012) and Koster

22 and Koster (2015) or to analyze behavioral tendencies such as the implications of prospect theory

23 (Hjorth and Fosgerau, 2012) and preference dynamics (Dekker, Koster and Brouwer, 2014).

24 However, none of these approaches used local discrete choice models to analyze spatial

25 heterogeneity - the issue considered in the present paper. Geographically weighted models for

26 discrete response variables have been employed in the past, but in rather different contexts, not 
1 connected with valuation of public goods, such as modelling urban growth (Luo and Kanala , 2008)

2 or predicting land use changes (Wang, Kockelman and Wang, 2011).

\section{Methodology}

4 We begin this section with a description of the geographically weighted multinomial logit. We 5 follow this with an explanation of the two-stage approach using location-specific WTP estimates 6 retrieved from the MXL model.

\section{The Geographically weighted multinomial logit model}

9 GWMNL model is defined as follows. A respondent $n$ 's utility from choosing alternative $i$ in the $j$-th

10 choice task is given by:

$$
U_{i j n}=V_{i j n}+\varepsilon_{i j n}=\boldsymbol{\beta}_{l}^{\prime} \mathbf{X}_{i j n}+\varepsilon_{i j n},
$$

12 where the error term $\varepsilon_{i j n}$ is assumed to be i.i.d with a Gumbel distribution. $\boldsymbol{\beta}_{l}$ is a set of parameters

13 for location 1 . The assumption which allows for the estimation of such a model is that individuals

14 located close to each other are assumed to have more similar preference parameters than

15 individuals located far away from each other, which is consistent with either of the directional

16 drivers in the introduction. As a result, the parameters become spatially correlated. For

17 convenience and ease of comparison between this approach and the approach used in Campbell,

18 Hutchinson and Scarpa (2009) and Czajkowski et al. (forthcoming-a) (described in detail below) we

19 estimated the GWMNL in WTP-space (Train and Weeks, 2005). This means that equation (1) was

20 reformulated as:

21

$$
\begin{aligned}
U_{i j n} & =\boldsymbol{\beta}_{l}^{\text {non-cost }} \mathbf{X}_{i j n}^{\text {non-cost }}-\beta_{l}^{\text {cost }} X_{i j n}^{\text {cost }}+\varepsilon_{i j n}= \\
& =\beta_{l}^{\text {cost }}\left(\frac{\boldsymbol{\beta}_{l}^{\text {non-cost }}{ }^{\prime}}{\beta_{l}^{\text {cost }}} \mathbf{X}_{i j n}^{\text {non-cost }}-X_{i j n}^{\text {cost }}\right)+\varepsilon_{i j n}=\beta_{l}^{\text {cost }}\left(\boldsymbol{\alpha}_{l}^{\prime} \mathbf{X}_{i j n}^{\text {non-cost }}-X_{i j n}^{\text {cost }}\right)+\varepsilon_{i j n}
\end{aligned}
$$

22 where now $\boldsymbol{\alpha}_{l}, \beta_{l}^{\text {cost }}$ are parameters to be estimated. 
1 Estimation of the GWMNL model is conducted by estimating $L$ 'local' models, where $L$ is a number

2 of distinct locations. In the case of our study, there were 253 distinct locations of respondents

3 (unique postal codes) and therefore this is the number of the local models. Each local model is

4 estimated via the weighted maximum likelihood method. The likelihood of individual $n$ making a

5 choice in a j-th choice task in the l-th local model is given by a standard multinomial logit formula:

6

$$
L_{j, n}^{l}=\prod_{i=1}^{I}\left(\frac{\exp \left(\boldsymbol{\beta}_{l}^{\prime} \mathbf{X}_{i j n}\right)}{\sum_{k} \exp \left(\boldsymbol{\beta}_{l}^{\prime} \mathbf{X}_{k j n}\right)}\right)^{y_{j i n}}
$$

7 The weighted log-likelihood for I-th model is defined as follows:

$$
W L^{l}=\sum_{n=1}^{N} \sum_{j=1}^{J} \lambda\left(\text { Lat }_{n}, \text { Long }_{n}, b, l\right) \log \left(L_{j, n}^{l}\right)
$$

9 where $\lambda\left(\right.$ Lat $_{n}$, Long $\left._{n}, b, l\right)$ is a geographical weight (kernel), which depends on latitude and 10 Iongitude of individual $n$ 's location, $b$ which is called the 'bandwidth parameter' and the location I

11 for which the local model is estimated. In order to take the panel nature of the data into account, 12 we have calculated robust standard errors that are clustered at the individual level. Note that 13 geographically weighted models normally use projected data, with the location given as metric 14 coordinates $X$ and $Y$ (easting and northing), to avoid having to use the complex and computationally 15 time-consuming 3D calculation of geographic distance with the two angular coordinates (latitude 16 and longitude) and indeed this was the same in our case. However, for clarity and to avoid potential 17 confusion with independent variables $\mathbf{X}_{i j n}$ we refer to the two projected coordinates ( $\mathrm{X}$ and $\mathrm{Y}$ ) 18 here as longitude and latitude respectively. There are a few functional forms of $\lambda(\cdot)$ proposed in 19 the literature. In what follows, we use the Gaussian kernel defined as:

$$
\lambda\left(\text { Lat }_{n}, \text { Long }_{n}, b, l\right)=\exp \left(-0.5 \frac{\left(\text { Lat }_{n}-\text { Lat }_{l}\right)^{2}+\left(\text { Long }_{n}-\text { Long }_{l}\right)^{2}}{b^{2}}\right)
$$

21 This is simply an exponential function of minus half of squared Euclidean distance of individual $n$ 's 22 location from location / divided by the square of the bandwidth parameter. If a respondent lives 
1 exactly in location I - this weight is equal to $1.1^{1}$ The use of this weight implies the clustering of

2 similar values because observations near to location $l$ have a larger bearing on the local model's

3 log-likelihood compared to observations that are further away. The bandwidth parameter

4 therefore determines what "further away" means. If the bandwidth is low, then practically only

5 the observations in very close proximity of given location influence the local model. Specifically,

6 when $b \rightarrow 0$ each local model is estimated using observations only from the given location.

7 Analogously, when bandwidth is high, all local models will have similar parameter estimates, with

$8 \quad b \rightarrow \infty$ leading to a simple MNL model for the whole sample.

9 It is worth noting, that the choice of bandwidth may have a greater impact on the results than the

10 choice of a specific weighting scheme (Fosgerau, 2007). There are several methods for choosing

11 the bandwidth parameter available in the literature, with no apparent dominant approach. We

12 tested three approaches, namely: using the corrected Akaike Information Criterion (AIC, Dekker,

13 Koster and Brouwer, 2014), taking the lowest bandwidth for which all local models converge

14 (Dekker, Koster and Brouwer, 2014), and using leave-one-individual-out cross-validation criterion

15 (Fotheringham, Brunsdon and Charlton, 2003). To evaluate these, we used simulated data which

16 utilized the designs utilized in our study. The results indicated that the available methods led to

17 either under or over-smoothing and were unsatisfactory - a conclusion also voiced by Koster and

18 Koster (2015). We therefore decided to use the 'eye-balling' approach they propose. In this

19 approach, a researcher chooses the lowest bandwidth for which the model estimates satisfy a set

20 of a priori specified conditions (e.g., achieving identification of all the models or avoiding extreme

21 estimates). Pagan and Ullah (1999) recommend using this approach when the number of

22 bandwidth parameters is not greater than 2, which is the case in our analysis. We decided that all

${ }^{1}$ For robustness check, we also tried different weighting functions, such as the spatially varying kernel (Fotheringham, Brunsdon and Charlton, 2003): $\lambda\left(\operatorname{Lat}_{n}, \operatorname{Long}_{n}, b, l\right)=\exp \left(-\frac{R_{n, l}}{b}\right)$, where $R_{n, l}$ is the rank of the $n$-th location from $l$-th location in terms of the distance $n$ is from $l$. The results were not much different from the Gaussian kernel. 
1 WTP estimates should lie in interval $[-100,100]$ EUR, for results to be reliable. Bandwidths that

2 result in WTP estimates outside of this range can be considered as inappropriate.

4 Sample size

5 There is a concern regarding the size of sample needed to calculate a local model with reliable 6 parameter estimates. Generally, the literature provides little guidance in this regard. Sample sizes

7 and the number of local models vary greatly depending on the application. In the cases where

8 secondary survey data are used, such as in the case of house prices (Cho, Poudyal and Roberts, 9 2008; Saphores and Li, 2012), school performance (Fotheringham, Charlton and Brunsdon, 2001)

10 or land use (Wang, Kockelman and Wang (2011), the number of observations is typically high, 11 ranging from around 3,700 to 50,000. Although, sometimes, for each observation there is 12 estimated a separate local model. Applications using stated preference methods usually make use 13 of much smaller datasets. For example, Fosgerau (2007) used data from 2000 respondents with 8 14 choice tasks per person and estimate 441 local models. Börjesson, Fosgerau and Algers (2012) 15 estimated the local models using responses from 1317 individuals. Koster and Koster (2015) used 16 a dataset of 487 individuals, and reported a local model for each. In this respect, our sample does 17 not seem to be "too small", especially when considering the number of individuals per location.

18 Nevertheless, as noted by one of our reviewers, for the GWMNL model the distribution of the 19 individuals across the space maybe a bigger issue than the sample size. When there are locations 20 with a low number of individuals, which are far away from any other individuals, the bandwidth 21 needs to increase to provide any meaningful estimates (the bias-variance trade-off). Also, the 22 locations with very high number of individuals may influence estimates of other local models 23 unproportionally. Unfortunately, for now, the effect of the sampling on spatial distribution of WTP 24 is not well researched, and it is not clear how it may affect the results.

26 The Location specific mixed logit model

27 The baseline for the comparison of the performance of GWMNL approach is provided by the 28 location-specific conditional distributions retrieved from the mixed logit model (Czajkowski et al., 
1 forthcoming) which can be estimated in WTP-space. In this model, respondent $n$ 's utility from 2 choosing alternative $i$ in the $j$-th choice task is given by:

$$
U_{i j n}=\beta_{l}^{\text {cost }}\left(\boldsymbol{\alpha}_{l}^{\prime} \mathbf{X}_{i j n}^{\text {non-cost }}-X_{i j n}^{\text {cost }}\right)+\varepsilon_{i j n} .
$$

4 We assume that each location / has a separate, independent set of parameters and therefore, we 5 assume that all individuals within given location have homogeneous preferences. We prefer this 6 specification over usual, aspatial individual-specific one, because it is more comparable with the 7 GWMNL approach. The usual, individual-specific MXL takes into account different sources of 8 heterogeneity, while the GWMNL accounts for the spatial heterogeneity only.

9 Location-specific parameters are not directly observed, but it is possible to estimate their values 10 implied by each respondents' choices conditional on the population-level estimates of parameter 11 distributions (Bayesian posterior means) using the Bayes theorem:

$$
E\left(\boldsymbol{\alpha}_{l} \mid \mathbf{y}_{l}, \mathbf{X}_{l}, \theta\right)=\int \boldsymbol{\alpha}_{l} \frac{p\left(\mathbf{y}_{l} \mid \mathbf{X}_{l}, \theta, \boldsymbol{\alpha}_{l}, \beta_{l}^{\text {cost }}\right) f\left(\boldsymbol{\alpha}_{l}, \beta_{l}^{\text {cost }} \mid \theta\right)}{p\left(\mathbf{y}_{l} \mid \mathbf{X}_{l}, \theta\right)} d\left(\boldsymbol{\alpha}_{l}, \beta_{l}^{\text {cost }}\right),
$$

13 where $p\left(\mathbf{y}_{l} \mid \mathbf{X}_{l}, \theta, \boldsymbol{\alpha}_{l}, \beta_{l}^{\text {cost }}\right)$ is the likelihood of all individuals from location / making the observed

14 choices conditional on the values of random parameters, $p\left(\mathbf{y}_{l} \mid \mathbf{X}_{l}, \theta\right)$ is the same likelihood but

15 unconditional (so it is likelihood function for $\mathrm{MXL}$ ) and $f\left(\boldsymbol{\alpha}_{l}, \beta_{l}^{\text {cost }} \mid \theta\right)$ is the assumed pdf function 16 of random parameters (normal distribution for all attributes except for the cost, which was 17 assumed to be log-normally distributed). For more details about this approach see Czajkowski et 18 al. (forthcoming).

19 Note, that contrary to the MXL model, in the GWMNL there is no need to specify a distribution 20 from which the parameters are drawn. It is also important to note that in this specification the MXL 21 model parameters associated with different locations are independent. Spatial dependence is, 22 therefore, accommodated indirectly as it arises from the calculation of conditional expected values 23 of random parameters. 
2 The original survey was conducted in 2010 on a representative sample ${ }^{2}$ of 1001 Polish adults. The 3 main objective of the survey was estimate public preferences over management options for the 4 national forest area (rather than specific local forests). The attributes used to describe these 5 management options were (1) passive protection of the most ecologically valuable forests, ${ }^{3}(2)$ 6 reducing the amount of litter (garbage, rubbish) in forests through tougher law enforcement and 7 by increasing forest cleaning services and (3) increasing the level of recreational infrastructure, 8 such as improved signposting of forest trails. The dataset used in this study was also exploited in 9 in Czajkowski et al. (2014) and Czajkowski, Giergiczny and Greene (2014), where the attributes, 10 experimental design and sampling strategy are described in detail.

11 Information on forest characteristics used in this study was obtained from two different sources.

12 Firstly, the CORINE Land Cover (CLC) dataset was used. This project is coordinated by the European 13 Environment Agency with the objective of collecting high resolution data for the whole continent. ${ }^{4}$ 14 CLC databases contain area data for objects with a minimum area of 5 ha and a width of more than 15100 meters. The second source of information used was the Polish Information System of State 16 Forests. This contains very precise data about the characteristics of forests in Poland. The data

17 from these sources was aggregated to $10 \times 10 \mathrm{~km}$ squares. ${ }^{5}$ In total, 3,307 such squares cover the

\footnotetext{
${ }^{2}$ We hired a professional polling agency that collected the questionnaires using high-quality, face-to-face computerassisted surveying techniques. A multi-stage sampling strategy was employed, in which communities were randomly selected to represent different community types, and then within each of the selected communities. A starting point address was randomly selected and then a set of addresses was chosen using the random route method. Finally, a random selection of an adult household member was employed.

${ }^{3}$ By passive (as opposed to active) protection of the forest, we mean leaving the forest ecosystem without any human intervention, even if this results in (natural) changes in ecosystems. It was highlighted that passive protection does not preclude recreational use.

${ }^{4}$ See http://www.eea.europa.eu/publications/COR0-landcover for further information on the CORINE program.

${ }^{5}$ We also tested aggregating the $50 \times 50 \mathrm{~km}$ resolution which provided equivalent results, although model fits were
} 
1 area of Poland. Figure 2 presents a map with a distribution of DCE study respondents. The GIS data 2 were associated with particular respondents using their ZIP-codes identifying their place of 3 residence. For every respondent, the explanatory variables were calculated as weighted averages 4 of forest characteristics in the $10 \times 10 \mathrm{~km}$ area common with respondents' ZIP area code. The GIS 5 variables used in this study are described in Table 1.

7 Figure 2. Respondents and forest area spatial distribution (red dots denote respondents' place of $8{\text { living })^{6}}^{2}$

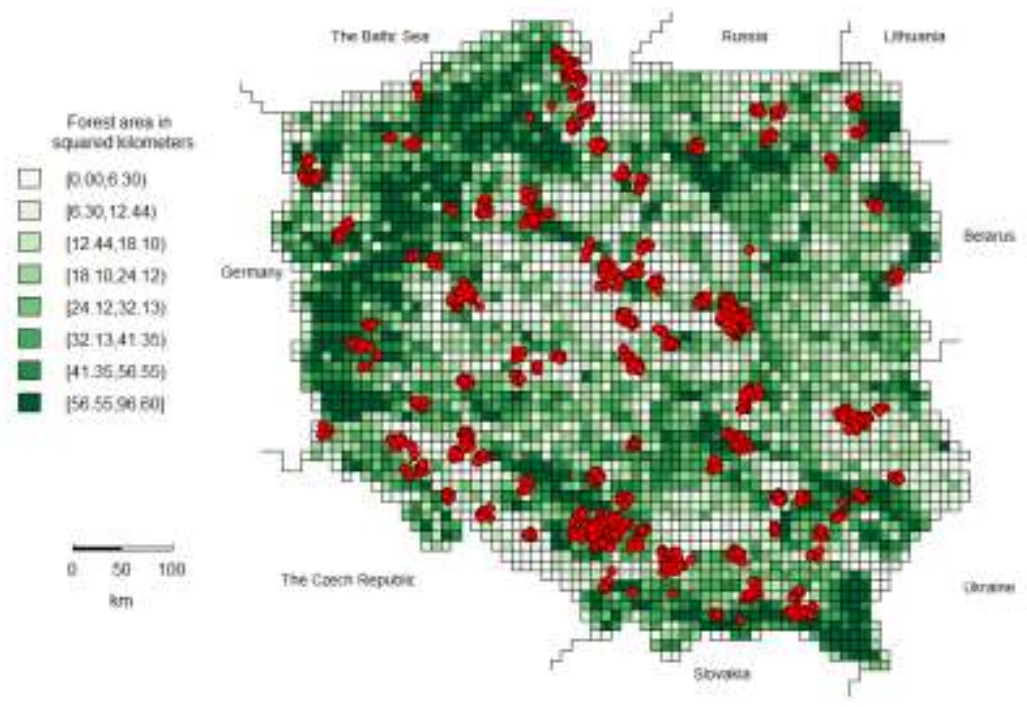

inferior.

${ }^{6}$ As some respondents reported the same ZIP-codes we jittered all of them with uniform random variable on [-5,5] $\mathrm{x}$ $[-5,5] \mathrm{km}$ square. This also allow us to compute spatial weights matrix. 
1 Table 1. GIS variables used to characterize the locations in which respondents' lived

\begin{tabular}{|c|c|c|c|c|}
\hline Variable name & Description & Source & Mean & St. Dev. \\
\hline $\begin{array}{l}\text { Area of coniferous } \\
\text { forests }\end{array}$ & Sum of areas of all coniferous forests $\left[\mathrm{km}^{2}\right]$ & Corine Land Cover & 11.3202 & 13.3060 \\
\hline $\begin{array}{l}\text { Area of deciduous } \\
\text { forests }\end{array}$ & Sum of areas of all deciduous forests $\left[\mathrm{km}^{2}\right]$ & Corine Land Cover & 4.2290 & 3.9805 \\
\hline $\begin{array}{l}\text { Area of mixed } \\
\text { forests }\end{array}$ & Sum of areas of all mixed forests $\left[\mathrm{km}^{2}\right]$ & Corine Land Cover & 6.5767 & 6.1084 \\
\hline $\begin{array}{l}\text { Average Euclidean } \\
\text { distance to forest }\end{array}$ & $\begin{array}{l}\text { It is average distance from any point in } \\
10 \times 10 \mathrm{~km} \text { square to the nearest forest }\end{array}$ & Corine Land Cover & 1.3075 & 0.8921 \\
\hline $\begin{array}{l}\text { Area of forests } \\
\text { with age }>120\end{array}$ & $\begin{array}{l}\text { Sum of areas of all forests older than } 120 \\
\text { years }\left[\mathrm{km}^{2}\right]\end{array}$ & $\begin{array}{l}\text { Information System } \\
\text { of State Forests }\end{array}$ & 0.9586 & 1.3336 \\
\hline $\begin{array}{l}\text { Area of forests } \\
\text { with the number of } \\
\text { species }>6\end{array}$ & $\begin{array}{l}\text { Sum of areas of all forests with the number } \\
\text { of tree species greater than } 6\left[\mathrm{~km}^{2}\right]\end{array}$ & $\begin{array}{l}\text { Information System } \\
\text { of State Forests }\end{array}$ & 5.9285 & 7.1911 \\
\hline Built-up area & Built-up area $\left[\mathrm{km}^{2}\right]$ & Corine Land Cover & 19.5532 & 19.3520 \\
\hline
\end{tabular}

3 The input for our geographically weighted models was the spatial data set of the respondents,

4 where the location was given as coordinates of ZIP-codes, and the locations were linked to

5 responses and environmental variables. Prior to running the GWMNL model, the original WGS1984

6 coordinates were projected using the ETRS_1989_Poland_CS92 coordinate system and the

7 projected coordinates were normalized.

8 The sample used in our study, 1001 individuals with 26 choice tasks per respondent, is sufficient

9 for estimation of 253 local models. Note that number of individuals vary between locations, with

10 some locations having only one individual, and some having more than 10 individuals. This result

11 in unbalanced panel, which may make estimates for locations with small number of individuals

12 imprecise. Specifically, in the case of MXL, when number of individuals in the given location is small,

13 the Bayesian posterior will be dominated by the chosen mixing distribution. In the case of GWMNL,

14 the estimation of local models involves a tradeoff of bias and variance of estimates (Fotheringham,

15 Brunsdon and Charlton, 2003). Nevertheless, if parameters values change continuously

16 throughout space the properly chosen bandwidth should provide reliable estimates for local

17 models. 
2 Following the approach outlined earlier, we estimated the GWMNL models for each of the 253

3 distinct locations in which our 1,001 respondents were located. ${ }^{7}$ Table 2 presents the summary

4 statistics of the estimated parameters for this model, which are compared with results from the

$5 \mathrm{MNL}$ and the location-specific MXL models. ${ }^{8}$ For the GWMNL model, we present means and

6 standard deviations of parameter estimates across 253 local models, which allows for

7 straightforward comparison with parameters from MXL model.

9 Table 2. Results of the MNL, location specific MXL and GWMNL models (standard errors in brackets,

10 coefficients in WTP-space, in EUR per year ${ }^{9}$ ).

\begin{tabular}{lccccc}
\hline & \multicolumn{2}{c}{ MNL model } & \multicolumn{2}{c}{ Location specific MXL model } & \multicolumn{2}{c}{ GWMNL } \\
\cline { 2 - 6 } Variable & \multicolumn{2}{c}{ Mean } & Std. Dev. & Mean & Std. Dev. \\
\cline { 2 - 6 } & $\begin{array}{c}\text { coef. } \\
\text { (st. err.) }\end{array}$ & $\begin{array}{c}\text { coef. } \\
\text { (st. err.) }\end{array}$ & $\begin{array}{c}\text { coef. } \\
\text { (st. err.) }\end{array}$ & $\begin{array}{c}\text { coef. } \\
\text { (st. err.) }\end{array}$ & $\begin{array}{c}\text { coef. } \\
\text { (st. err.) }\end{array}$ \\
\hline$N A T_{1}$ & $14.8307^{* * *}$ & $11.7961^{* * *}$ & $7.6114^{* * *}$ & $15.7107^{* * *}$ & $6.8786^{* * *}$ \\
$\begin{array}{l}\text { (passive protection of most valuable } \\
\text { forests - partial improvement) }\end{array}$ & $(0.5673)$ & $(0.4288)$ & $(0.4559)$ & $(0.1258)$ & $(0.1701)$ \\
$N A T_{2}$ & $21.8207^{* * *}$ & $16.8630^{* * *}$ & $12.1756^{* * *}$ & $23.0767^{* * *}$ & $10.0173^{* * *}$ \\
$\begin{array}{l}\text { (passive protection of most valuable } \\
\text { forests - substantial improvement) }\end{array}$ & $(0.7248)$ & $(0.6129)$ & $(0.6531)$ & $(0.1826)$ & $(0.2575)$ \\
$\begin{array}{l}\text { TRA } \\
\text { (the amount of litter in forests - partial }\end{array}$ & $26.6697^{* * *}$ & $17.4477^{* * *}$ & $8.3347^{* * *}$ & $28.3018^{* * *}$ & $11.0293^{* * *}$ \\
$\begin{array}{l}\text { improvement) } \\
T R A_{2} \\
\text { (the amount of litter in forests }-\end{array}$ & $(0.8298)$ & $(0.6066)$ & $(0.4433)$ & $(0.2001)$ & $(0.2316)$ \\
substantial improvement) & $35.6782^{* * *}$ & $25.2329^{* * *}$ & $14.1371^{* * *}$ & $37.8590^{* * *}$ & $14.7594^{* * *}$ \\
& $(1.0664)$ & $(0.9080)$ & $(0.7508)$ & $(0.2721)$ & $(0.3624)$
\end{tabular}

\footnotetext{
${ }^{7}$ In the estimation, we used the bandwidth parameter of 0.475 which was the lowest value to satisfy our a priori (albeit arbitrarily) specified condition that all models converge and in no location the estimated WTP is larger than 100 EUR. See section 3.1 for discussion and Appendix A for the robustness analysis of this assumption.

${ }^{8}$ Standard errors for the GWMNL model estimates were Monte-Carlo simulated using 10,000 repetitions, in which parameters of every locally estimated model were assumed to follow multivariate normal distribution.

${ }^{9}$ At 1 PLN $\approx 0.23 \mathrm{EUR} \approx 0.25 \mathrm{USD}$.
} 


\begin{tabular}{|c|c|c|c|c|c|}
\hline $\begin{array}{l}I N F_{1} \\
\text { (tourist infrastructure } \quad-\quad \text { partial } \\
\text { improvement) }\end{array}$ & $\begin{array}{c}12.1400^{* * *} \\
(0.5269)\end{array}$ & $\begin{array}{c}8.2641^{* * *} \\
(0.3997)\end{array}$ & $\begin{array}{c}4.5826^{* * *} \\
(0.3251)\end{array}$ & $\begin{array}{c}12.7121^{* * *} \\
(0.0915)\end{array}$ & $\begin{array}{c}5.1219 * * * \\
(0.1003)\end{array}$ \\
\hline$I N F_{2}$ & $19.5598 * * *$ & $12.1145^{* * *}$ & $6.5138^{* * *}$ & $20.6085^{* * *}$ & $8.2931 * * *$ \\
\hline $\begin{array}{l}\text { (tourist infrastructure - substantial } \\
\text { improvement) }\end{array}$ & $(0.6553)$ & $(0.5044)$ & $(0.3723)$ & $(0.1388)$ & $(0.1543)$ \\
\hline SQ & $37.2443^{* * *}$ & $-3.2461 * * *$ & $43.2764^{* * *}$ & $39.3765^{* * *}$ & $26.2943^{* * *}$ \\
\hline $\begin{array}{l}\text { (alternative specific constant for the } \\
\text { no-choice alternative) }\end{array}$ & $(1.4032)$ & $(0.7457)$ & $(2.1355)$ & $(0.3866)$ & $(0.4566)$ \\
\hline COST & $0.0538 * * *$ & $-2.2472 * * *$ & $0.7066^{* * *}$ & $0.0575^{* * *}$ & $0.0240 * * *$ \\
\hline (annual cost - tax increase) & $(0.0014)$ & $(0.0400)$ & $(0.0245)$ & $(0.0004)$ & $(0.0005)$ \\
\hline \multicolumn{6}{|l|}{ Model characteristics } \\
\hline Log-likelihood (constant only) & $-36,045.3765$ & \multicolumn{2}{|c|}{$-36,045.3765$} & \multicolumn{2}{|c|}{$-36,045.3765$} \\
\hline Log-likelihood & $-29,708.2771$ & \multicolumn{2}{|c|}{$-22,632.3017$} & \multicolumn{2}{|c|}{$-28,555.9663^{10}$} \\
\hline Ben-Akiva Lerman's pseudo- $\mathrm{R}^{2}$ & 0.3282 & \multicolumn{2}{|c|}{0.4626} & \multicolumn{2}{|c|}{$0.3550^{14}$} \\
\hline McFadden's pseudo- $R^{2}$ & 0.3308 & \multicolumn{2}{|c|}{0.3721} & \\
\hline $\mathrm{AlC} / \mathrm{n}$ & 2.2836 & \multicolumn{2}{|c|}{1.7426} & \multicolumn{2}{|c|}{$2.1950^{14}$} \\
\hline$n$ (observations) & 26,026 & \multicolumn{2}{|c|}{26,026} & \multicolumn{2}{|c|}{26,026} \\
\hline k (parameters) & 8 & \multicolumn{2}{|c|}{44} & & \\
\hline
\end{tabular}

3 As our model was estimated in WTP-space, parameters for all attributes can be interpreted directly 4 as willingness to pay. Qualitative results mimic those found in Czajkowski et al. (forthcoming), 5 namely that on average the individuals are willing to pay the most for reducing of amount of litter 6 and the least for improvements in infrastructure.

7 The comparison of WTP characteristics between the models reveals that means of the GWMNL 8 estimates are very close to MNL estimates. In contrast, for the location-specific MXL the mean WTP 9 values are significantly lower. The biggest difference is observed for the mean estimates of 10 alternative specific constant parameter (SQ) which has a reversed sign. Finally, we note that the 11 standard deviations are of similar magnitude in both approaches (except for SQ which has a higher 12 standard deviation in the location-specific MXL model).

\footnotetext{
${ }^{10}$ For GWMNL these are mean values across 253 local models
} 
1 There are, at least, three possible reasons for why we observe significant changes in the mean WTP

2 values. Firstly, one can expect that not allowing for spatial correlation in the specification of the

3 MXL model may lead to biased estimates. Secondly, the assumption of the MNL model form of

4 local models in GWMNL may not be justified, because the error terms could in reality be correlated

5 across alternatives. Lastly, and crucially, it may be driven by the distributional assumptions of the

$6 \mathrm{MXL}$ model. While the MXL model assumes that the cost*scale parameter is log-normally

7 distributed and that the marginal WTP distributions are all normally distributed, the GWMNL

8 model is a semi-parametric approach and thus makes no such assumptions.

9 In order to compare the relative fit to the data provided by each of the three models (GWMNL,

10 MNL and location -specific MXL models) we propose to use the Ben-Akiva-Lerman's pseudo- ${ }^{2}$

11 (Ben-Akiva and Lerman, 1985). This is a measure of predicted probabilities of choosing the

12 alternatives which were actually chosen by respondents - an intuitive way of illustrating how well

13 a model predicts the observed choices. We adapt this measure to the panel character of our data

14 - because each respondent or each location was associated with $n$ choice tasks, the joint 15 probability of the observed series of $n$ choices is normalized by taking its $n$-th root. Mean 16 probabilities are presented in Table 2 (Ben-Akiva-Lerman's pseudo- $R^{2}$ ), while their spatial 17 distribution is illustrated in Figure 3. The pattern that emerges is clear - although the GWMNL 18 approach provides a better fit than the MNL model, it is worse than the location-specific MXL 19 model. Apparently the ability to generically account for the unobserved preference heterogeneity 20 offers more of an improvement in fit than explicitly accounting for spatial correlations in the MNL

21 model. However, we note that the predicted probabilities are highly correlated - the regions in

22 which respondents' choices are relatively better or worse predicted are unchanged across the four

23 models. This observation is further illustrated with the results provided in Table 3 - the correlation

24 coefficients between location specific choice probabilities predicted by different models. Indeed,

25 the predictions from GWMNL are more correlated with MNL, than with MXL.

26 Figure 3. Model-specific predicted probabilities of the observed choices (Ben-Akiva-Lerman's 27 pseudo- $\left.R^{2}\right)$ 


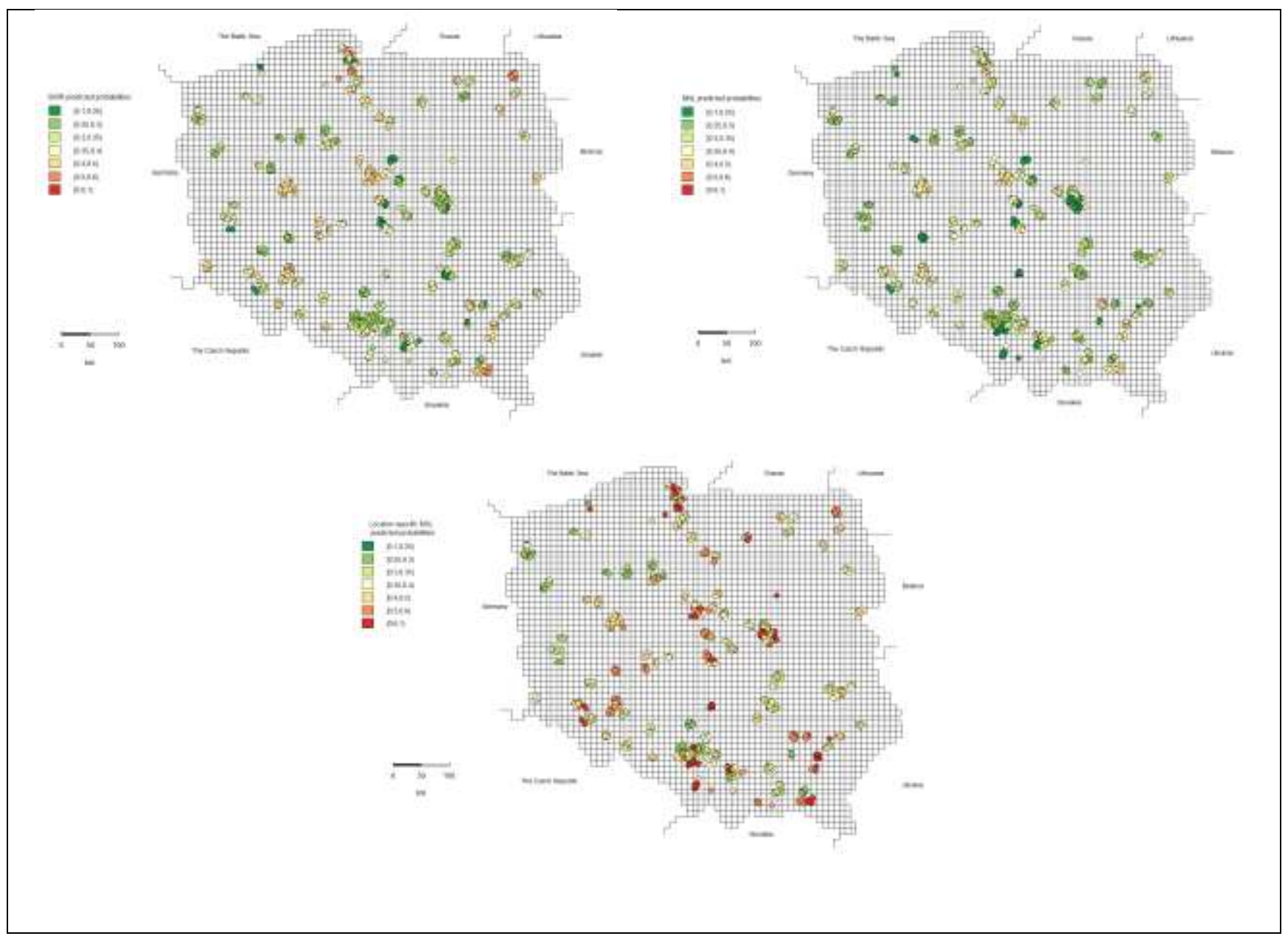

1

2 Table 3. Correlation coefficients of model-specific predicted probabilities of the observed choices

3 (Ben-Akiva-Lerman's pseudo- $\mathrm{R}^{2}$ )

\begin{tabular}{cccc}
\hline & GWMNL $(b=0.475)$ & MNL & $\begin{array}{c}\text { Location specific } \\
\text { MXL model }\end{array}$ \\
\cline { 2 - 4 } GWMNL $(b=0.475)$ & 1.0000 & 0.7782 & 0.4110 \\
MNL & 0.7782 & 1.0000 & 0.2313 \\
$\begin{array}{c}\text { Location specific } \\
\text { MXL model }\end{array}$ & 0.4110 & 0.2313 & 1.0000
\end{tabular}

4

5 In order to analyze the discrepancies between the geographically weighted and the traditional two-

6 step approach further we can compare the differences between WTP estimates for every location

7 presented on map of Poland. This is done in the 7 panels of Figure 4 . In these panels positive values 
1 depict locations where GWMNL ( $b=0.475$ ) estimates are higher (red) and negative values depict

2 locations where conditional expected values from location-specific MXL are higher (green).

3 Distributions of these differences are not symmetric with respect to 0 (as every interval consists of

$410 \%$ of the sample). For all attributes, more than $80 \%$ of observations have positive values (higher

5 values of WTP from GWMNL).

6 Graphical analysis reveals several spatial patterns of between-estimate differences which are

7 consistent across all attributes. First of all, the largest differences can be observed in the central-

8 south part of Poland near Cracow and Katowice cities, where GWMNL approach leads to much

9 higher estimates of WTP. Secondly, in the west and north-east parts of Poland the differences seem

10 to be much lower, sometimes negative. In the other parts of the country there is no clear spatial

11 pattern, although it seems that also in the central part the differences are rather low (but positive).

12 The fact, that some spatial patterns can be observed is an indication that these the two approaches

13 recover different spatial dependencies of preferences. As GWMNL is designed to recover such

14 spatial dependencies we can expect it to work better in this regard.

15 In order to investigate any systematic dependencies in these differences we estimated simple

16 linear regressions in which their absolute values are explained by GIS variables and the number of

17 observations per location. The full results are available in Appendix B. In short, we found that for

18 locations with higher number of observations differences in WTP are significantly lower. This may

19 indicate, that with more homogeneous sampling (with multiple observations per location) the two

20 methods become more similar. What is more, we found that the differences are lower in areas

21 with high coverage of very old forests, but are higher in built-up areas and areas with high coverage

22 of forests with more than 6 tree species.

23

24 Figure 4. Spatial distribution of differences between WTP estimates from GWMNL and conditional 25 expected values from location-specific MXL. 

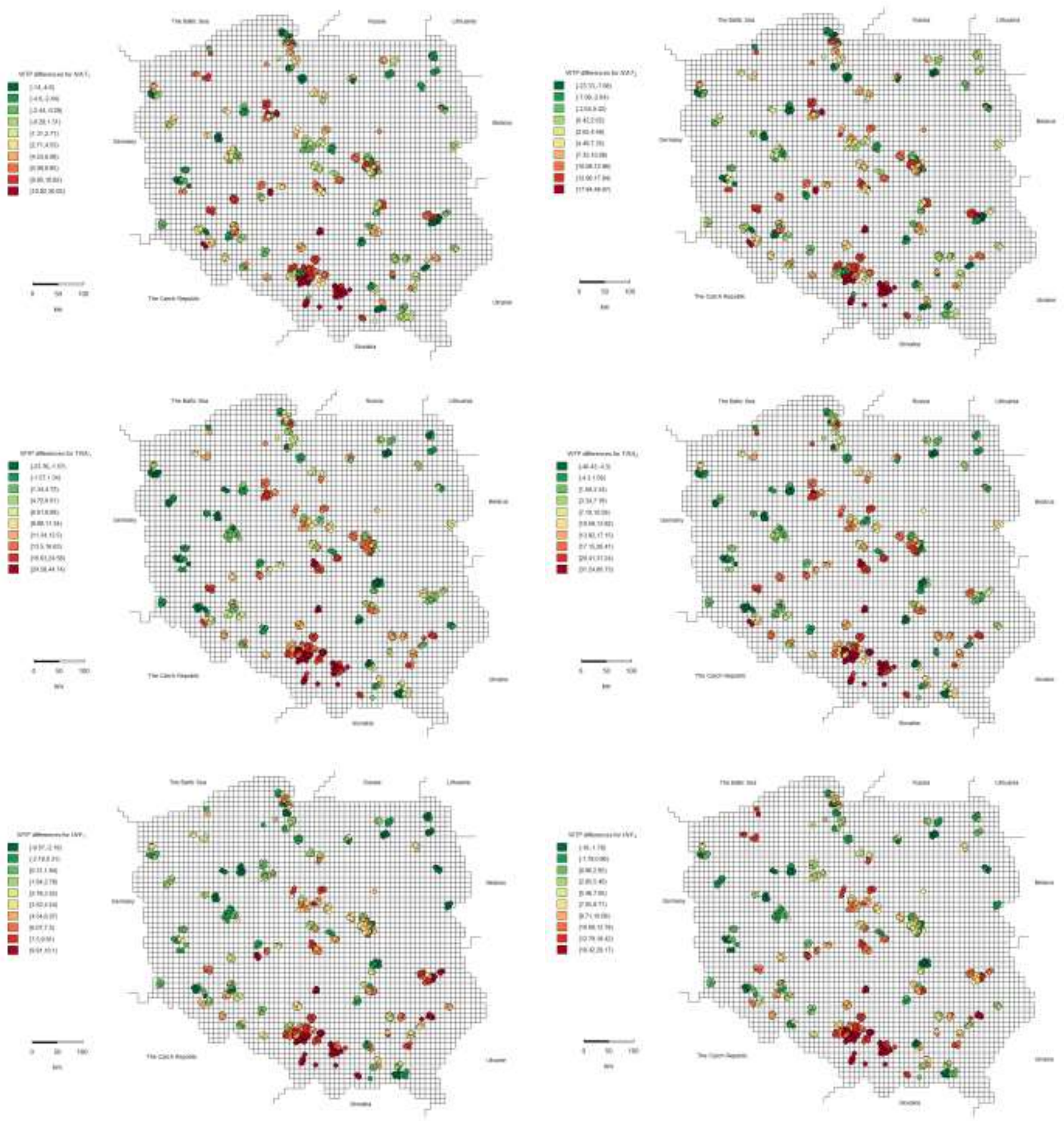


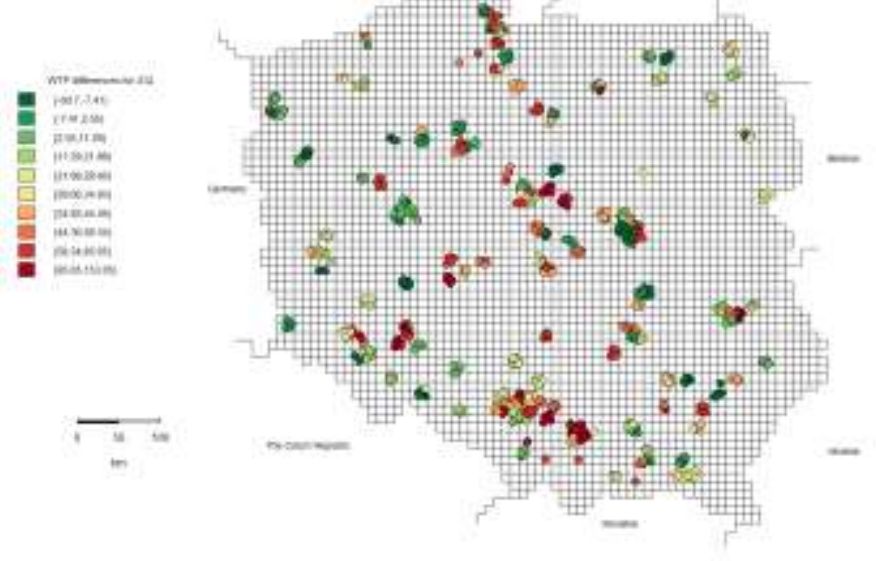

2 Lastly, it is possible to perform a decomposition of the estimated WTP using GIS variables, similar

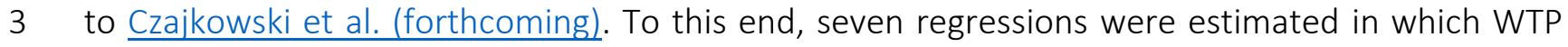

4 were explained by the same GIS variables as in Czajkowski et al. (forthcoming). The results from

5 linear regression model on the GWMNL $(b=0.475)$ results are given in Table 4, whereas the spatial

6 lag models based on the conditional expected values of random parameters from location-specific

$7 \mathrm{MXL}$ are presented in Table $5 .{ }^{11}$ In all cases we decided to use only GIS variables and omit socio-

8 demographic variables, since these were insignificant in most cases for the GWMNL and location-

9 specific $M X L$ approaches. Testing their joint significance we found that at 5\% significance level

10 socio-demographic variables are significant only in $N A T_{1}$ and $N A T_{2}$ equations, and not significant in

11 any equation at $1 \%$ significance level. We think that these results may be caused partly by the fact

12 that we needed to average socio-demographic variables over individuals in the same location, as

13 in Czajkowski et al. (forthcoming), where this relationship was analyzed on the individual level,

14 socio-demographic variables were more significant.

\footnotetext{
${ }^{11}$ Note that in current analysis we used Ordinary Least Square instead of spatial lag model. It was not possible to estimate spatial lag model on WTP estimated from GWMNL as from definition these are highly spatially autocorrelated and therefore coefficient $\rho$ (which is coefficient for spatial lag term) was almost equal to 1 and no other variable would then occur significant.
} 
1 Looking firstly at the results based on the GWMNL results, we find that most of GIS variables are

2 highly significant. We can compare these estimates with results in Table 5 in order to investigate

3 structural differences in spatial heterogeneity in WTP estimates between the GWMNL and

4 Bayesian posterior means from location-specific MXL. Greyed out cells of Table 4 indicate

5 coefficients which have a different sign than equivalent coefficients in Table 5. This issue is the

6 most prominent in regression for the $S Q$, where 3 variables have different signs, although they are

7 all insignificant in this case. This problem also occurs, for almost every attribute, with "Area of

8 forests with age $>120^{\prime \prime}$ variable. In case of location-specific MXL, this variable has a positive

9 (although insignificant) coefficient for most attributes. What is also interesting is that in the current

10 analysis variables "Built-up area" and "Area of forests with no. of species $>6$ " were significant in

11 almost all cases. This differs to what we discovered when using the conditional expected values of

12 random parameters from the MXL model where these variables were insignificant in all cases.

13

14 Table 4. Results of regressions in which WTP estimates from GWMNL are explained by GIS 15 variables

\begin{tabular}{|c|c|c|c|c|c|c|c|}
\hline & $\begin{array}{c}\text { SQ } \\
\text { (alternative } \\
\text { specific } \\
\text { constant for } \\
\text { the no-choice } \\
\text { alternative) }\end{array}$ & $\begin{array}{c}N A T_{1} \\
\text { (passive } \\
\text { protection of } \\
\text { most valuable } \\
\text { forests - } \\
\text { partial } \\
\text { improvement) }\end{array}$ & $\begin{array}{c}N A T_{2} \\
\text { (passive } \\
\text { protection of } \\
\text { most valuable } \\
\text { forests - } \\
\text { substantial } \\
\text { improvement) }\end{array}$ & $\begin{array}{c}T_{R A_{1}} \\
\text { (the amount } \\
\text { of litter in } \\
\text { forests - } \\
\text { partial } \\
\text { improvement) }\end{array}$ & $\begin{array}{c}T_{R A_{2}} \\
\text { (the amount } \\
\text { of litter in } \\
\text { forests - } \\
\text { substantial } \\
\text { improvement) }\end{array}$ & $\begin{array}{c}I^{N F_{1}} \\
\text { (tourist } \\
\text { infrastructure } \\
\text { - partial } \\
\text { improvement) }\end{array}$ & $\begin{array}{c}\mathrm{INF}_{2} \\
\text { (tourist } \\
\text { infrastructure } \\
\text { - substantial } \\
\text { improvement) }\end{array}$ \\
\hline Constant & $\begin{array}{c}34.7688^{* * *} \\
(5.7861)\end{array}$ & $\begin{array}{c}17.6132^{* * *} \\
(1.5842)\end{array}$ & $\begin{array}{c}27.0083^{* * *} \\
(2.4027)\end{array}$ & $\begin{array}{c}30.8844^{* * *} \\
(2.4394)\end{array}$ & $\begin{array}{c}44.8497^{* * *} \\
(3.4203)\end{array}$ & $\begin{array}{c}11.8696 * * * \\
(1.0303)\end{array}$ & $\begin{array}{c}22.0946 * * * \\
(1.8038)\end{array}$ \\
\hline $\begin{array}{l}\text { Area of } \\
\text { coniferous } \\
\text { forests }\end{array}$ & $\begin{array}{l}-0.1544 \\
(0.1362)\end{array}$ & $\begin{array}{l}-0.0727^{*} \\
(0.0373)\end{array}$ & $\begin{array}{l}-0.1088^{*} \\
(0.0566)\end{array}$ & $\begin{array}{l}-0.0732 \\
(0.0574)\end{array}$ & $\begin{array}{l}-0.1519 * \\
(0.0805)\end{array}$ & $\begin{array}{c}0.0239 \\
(0.0243)\end{array}$ & $\begin{array}{l}-0.0449 \\
(0.0425)\end{array}$ \\
\hline $\begin{array}{l}\text { Area of } \\
\text { deciduous } \\
\text { forests }\end{array}$ & $\begin{array}{l}1.0730 * * \\
(0.4567)\end{array}$ & $\begin{array}{l}-0.1207 \\
(0.1251)\end{array}$ & $\begin{array}{l}-0.3464 * \\
(0.1897)\end{array}$ & $\begin{array}{l}-0.0479 \\
(0.1926)\end{array}$ & $\begin{array}{l}-0.3411 \\
(0.2700)\end{array}$ & $\begin{array}{c}0.2376 * * * \\
(0.0813)\end{array}$ & $\begin{array}{c}0.2164 \\
(0.1424)\end{array}$ \\
\hline $\begin{array}{l}\text { Area of mixed } \\
\text { forests }\end{array}$ & $\begin{array}{l}-0.1680 \\
(0.3356)\end{array}$ & $\begin{array}{c}-0.2419 * * * \\
(0.0919)\end{array}$ & $\begin{array}{c}-0.3022^{* *} \\
(0.1393)\end{array}$ & $\begin{array}{c}-0.2930^{* *} \\
(0.1415)\end{array}$ & $\begin{array}{c}-0.4331^{* *} \\
(0.1984)\end{array}$ & $\begin{array}{l}-0.0364 \\
(0.0598)\end{array}$ & $\begin{array}{c}-0.2270 * * \\
(0.1046)\end{array}$ \\
\hline $\begin{array}{l}\text { Area of forests } \\
\text { with age }>120\end{array}$ & $\begin{array}{c}-7.0385 * * * \\
(1.4597)\end{array}$ & $\begin{array}{l}-0.4937 \\
(0.3996)\end{array}$ & $\begin{array}{l}-0.5343 \\
(0.6061)\end{array}$ & $\begin{array}{c}-1.3759 * * \\
(0.6154)\end{array}$ & $\begin{array}{l}-1.0958 \\
(0.8628)\end{array}$ & $\begin{array}{c}-1.4039 * * * \\
(0.2599)\end{array}$ & $\begin{array}{c}-2.0912 * * * \\
(0.4550)\end{array}$ \\
\hline $\begin{array}{l}\text { Average } \\
\text { Euclidean } \\
\text { distance to a } \\
\text { forest }\end{array}$ & -1.7794 & $-1.1623^{*}$ & $-1.7118^{*}$ & $\begin{array}{c}-2.3111^{* *} \\
(0.9917)\end{array}$ & $\begin{array}{c}-3.8154 * * * \\
(1.3904)\end{array}$ & $\begin{array}{l}0.0347 \\
(0.4189)\end{array}$ & $\begin{array}{l}-1.1040 \\
(0.7333)\end{array}$ \\
\hline Built-up area & $\begin{array}{c}0.2859 * * * \\
(0.0793)\end{array}$ & $\begin{array}{c}0.0813 * * * \\
(0.0217)\end{array}$ & $\begin{array}{c}0.1123 * * * \\
(0.0329)\end{array}$ & $\begin{array}{c}0.1454 * * * \\
(0.0334)\end{array}$ & $\begin{array}{c}0.1703 * * * \\
(0.0469)\end{array}$ & $\begin{array}{c}0.0129 \\
(0.0141)\end{array}$ & $\begin{array}{c}0.0405 \\
(0.0247)\end{array}$ \\
\hline $\begin{array}{l}\text { Area of forests } \\
\text { with no. of } \\
\text { species }>6\end{array}$ & $1.0447 * * *$ & $0.2774 * * *$ & $0.3147^{* *}$ & $0.3567^{* *}$ & $0.4133^{* *}$ & $0.1161^{*}$ & $0.3829 * * *$ \\
\hline
\end{tabular}




\begin{tabular}{|c|c|c|c|c|c|c|c|}
\hline & $(0.3331)$ & $(0.0912)$ & $(0.1383)$ & $(0.1405)$ & $(0.1969)$ & $(0.0593)$ & $(0.1039)$ \\
\hline \multicolumn{8}{|c|}{ Model characteristics } \\
\hline n (observations) & 253 & 253 & 253 & 253 & 253 & 253 & 253 \\
\hline
\end{tabular}

4 Table 5. Results of spatial lag models in which Bayesian posterior means from MXL model are 5 explained by GIS variables.

\begin{tabular}{|c|c|c|c|c|c|c|c|}
\hline & $\begin{array}{c}\text { SQ } \\
\text { (alternative } \\
\text { specific constant } \\
\text { for the no-choice } \\
\text { alternative) }\end{array}$ & $\begin{array}{c}N A T_{1} \\
\text { (passive } \\
\text { protection of } \\
\text { most valuable } \\
\text { forests - } \\
\text { partial } \\
\text { improvement) }\end{array}$ & $\begin{array}{c}\mathrm{NAT}_{2} \\
\text { (passive } \\
\text { protection of } \\
\text { most valuable } \\
\text { forests - } \\
\text { substantial } \\
\text { improvement) }\end{array}$ & $\begin{array}{c}T_{R A_{1}} \\
\text { (the amount } \\
\text { of litter in } \\
\text { forests - } \\
\text { partial } \\
\text { improvement) }\end{array}$ & $\begin{array}{c}T_{R A_{2}} \\
\text { (the amount } \\
\text { of litter in } \\
\text { forests - } \\
\text { substantial } \\
\text { improvement) }\end{array}$ & $\begin{array}{c}\text { INF } \\
\text { (tourist } \\
\text { infrastructure } \\
\text { - partial } \\
\text { improvement) }\end{array}$ & $\begin{array}{c}I N F_{2} \\
\text { (tourist } \\
\text { infrastructure } \\
\text { - substantial } \\
\text { improvement) }\end{array}$ \\
\hline \multicolumn{8}{|c|}{ Location-specific MXL } \\
\hline Constant & $\begin{array}{c}-35.0845 * * * \\
{[9.0012]}\end{array}$ & $\begin{array}{c}15.2120 * * * \\
{[1.9167]}\end{array}$ & $\begin{array}{c}23.2420^{* * *} \\
{[2.9933]}\end{array}$ & $\begin{array}{c}16.2849 * * * \\
{[2.1964]}\end{array}$ & $\begin{array}{c}26.6299 * * * \\
{[3.5287]}\end{array}$ & $\begin{array}{c}5.9459 * * * \\
{[1.0342]}\end{array}$ & $\begin{array}{c}8.9798 * * * \\
{[1.4828]}\end{array}$ \\
\hline $\begin{array}{l}\text { Area of coniferous } \\
\text { forests }\end{array}$ & $\begin{array}{c}0.4807^{* *} \\
{[0.2108]}\end{array}$ & $\begin{array}{c}-0.0828 * * \\
{[0.0371]}\end{array}$ & $\begin{array}{c}-0.1442 * * \\
{[0.0595]}\end{array}$ & $\begin{array}{l}-0.0674 * \\
{[0.0402]}\end{array}$ & $\begin{array}{c}-0.1537^{* *} \\
{[0.0668]}\end{array}$ & $\begin{array}{c}0.0054 \\
{[0.0202]}\end{array}$ & $\begin{array}{l}-0.0129 \\
{[0.0284]}\end{array}$ \\
\hline $\begin{array}{l}\text { Area of deciduous } \\
\text { forests }\end{array}$ & $\begin{array}{c}2.5479 * * * \\
{[0.6502]}\end{array}$ & $\begin{array}{c}-0.3785^{* * *} \\
{[0.1139]}\end{array}$ & $\begin{array}{c}-0.6469 * * * \\
{[0.1829]}\end{array}$ & $\begin{array}{l}-0.1931 \\
{[0.1226]}\end{array}$ & $\begin{array}{c}-0.5320 * * * \\
{[0.2043]}\end{array}$ & $\begin{array}{c}0.0471 \\
{[0.0616]}\end{array}$ & $\begin{array}{c}0.0096 \\
{[0.0867]}\end{array}$ \\
\hline $\begin{array}{l}\text { Area of mixed } \\
\text { forests }\end{array}$ & $\begin{array}{l}0.7688^{*} \\
{[0.4489]}\end{array}$ & $\begin{array}{c}-0.1880 * * \\
{[0.0791]}\end{array}$ & $\begin{array}{c}-0.3133^{* *} \\
{[0.1270]}\end{array}$ & $\begin{array}{c}-0.2060 * * \\
{[0.0859]}\end{array}$ & $\begin{array}{c}-0.3404 * * \\
{[0.1425]}\end{array}$ & $\begin{array}{l}-0.0634 \\
{[0.0430]}\end{array}$ & $\begin{array}{l}-0.1022 * \\
{[0.0607]}\end{array}$ \\
\hline $\begin{array}{l}\text { Area of forests } \\
\text { with age }>120\end{array}$ & $\begin{array}{l}-0.6381 \\
{[2.2125]}\end{array}$ & $\begin{array}{c}0.6013 \\
{[0.3907]}\end{array}$ & $\begin{array}{c}0.9906 \\
{[0.6268]}\end{array}$ & $\begin{array}{c}0.4653 \\
{[0.4225]}\end{array}$ & $\begin{array}{c}0.9354 \\
{[0.7025]}\end{array}$ & $\begin{array}{l}-0.0776 \\
{[0.2117]}\end{array}$ & $\begin{array}{c}0.0971 \\
{[0.2983]}\end{array}$ \\
\hline $\begin{array}{l}\text { Average Euclidean } \\
\text { distance to a } \\
\text { forest }\end{array}$ & $\begin{array}{c}10.8442 * * * \\
{[3.3104]}\end{array}$ & $\begin{array}{c}-1.6825 * * * \\
{[0.5811]}\end{array}$ & $\begin{array}{c}-2.8926 * * * \\
{[0.9328]}\end{array}$ & $\begin{array}{c}-1.6013^{* *} \\
{[0.6309]}\end{array}$ & $\begin{array}{c}-3.2686 * * * \\
{[1.0499]}\end{array}$ & $\begin{array}{c}-0.2967 \\
{[0.3153]}\end{array}$ & $\begin{array}{c}-0.6871 \\
{[0.4454]}\end{array}$ \\
\hline$\rho$ & $\begin{array}{c}0.2555^{* * *} \\
{[0.0723]} \\
\end{array}$ & $\begin{array}{c}0.1810 * * \\
{[0.0760]}\end{array}$ & $\begin{array}{c}0.1824 * * \\
{[0.0758]}\end{array}$ & $\begin{array}{c}0.3397 * * * \\
{[0.0681]} \\
\end{array}$ & $\begin{array}{c}0.3325 * * * \\
{[0.0682]} \\
\end{array}$ & $\begin{array}{c}0.3700 * * * \\
{[0.0664]}\end{array}$ & $\begin{array}{c}0.4090 * * * \\
{[0.0637]}\end{array}$ \\
\hline \multicolumn{8}{|c|}{ Model characteristics } \\
\hline Log Likelihood & -1255.8570 & -814.7967 & -934.2825 & -838.5166 & -966.3454 & -665.4564 & -753.4436 \\
\hline $\mathrm{AIC} / \mathrm{n}$ & 10.0246 & 6.5194 & 7.4643 & 6.7622 & 7.7718 & 5.4062 & 6.1279 \\
\hline n (observations) & 253 & 253 & 253 & 253 & 253 & 253 & 253 \\
\hline k (parameters) & 8 & 8 & 8 & 8 & 8 & 8 & 8 \\
\hline
\end{tabular}

8 Overall, the results indicate that there are significant discrepancies with regard to spatial patterns

9 recovered with the two methods. Differences in the signs and significance of coefficients for GIS

10 variables demonstrate that the WTP distributions differ in structure between these two

11 approaches. As the GWMNL model explicitly deals with spatial heterogeneity (rather than trying

12 to recover it indirectly post estimation) it could be considered more reliable. It is also important to 
1 note that in all models using the GWMNL estimates the $R^{2}$ in all models is very low, which suggest

2 that the GIS variables we used explain only a small fraction of the observed variance. Therefore,

3 assuming that the estimated values obtained from the GWMNL models are the true values, most

4 of the heterogeneity in WTP is caused by some other factors, which we do not account for. This

5 may partly be due to the spatial distribution of forest characteristics in Poland.

6

7 In some cases the differences between forests which lie next to each other are large, and therefore

8 significant variance in their values may occur even on a local level. Because of that, our model may

9 not be able to recover relationship between these factors and preference heterogeneity correctly,

10 as we do not have sufficiently detailed data to model this local variation. It is possible that the

11 GWMNL approach would perform better in the case of preferences for environmental goods which

12 change more gradually.

\section{Discussion and conclusions}

In this paper we investigate two alternative methods for addressing spatial patterns in willingness to pay for changes to an environmental good. We argued that knowledge of how willingness to pay for a specific environmental change varies across space is useful from a policy and management perspective. Knowing the spatial pattern of values can help resource managers target investments in site quality, or in new forests, as investments can be directed at locations where they are most valued. It also enables a higher-resolution identification of the gainers and losers from changes in resource management, since now the location of individuals who gain by a given amount from a policy can be mapped. An example of how important this might be is provided by Hynes et al (2010) using contingent valuation survey data for Ireland. They found that allowing for spatial differences in the characteristics of individuals (in their case, farmers) via a micro-simulation approach resulted in significantly different estimates of willingness to pay for biodiversity conservation at the regional level, and thus significantly different measures of aggregate benefits, compared to an aggregation method which did not take into account spatial variation in the characteristics of beneficiaries. 
1 Given the costs of original survey work, the ability to produce such maps cost-effectively is highly 2 desirable so long as results are sufficiently robust. The case study used to generate the data with 3 which the two alternative methods are tested concerns the management of forests in Poland. We 4 introduced a novel method of geographically weighted discrete choice models to account for 5 spatial heterogeneity of model parameters, and compared this to a standard "two-step" approach 6 using the MXL model and posterior Bayesian means of random parameters (Czajkowski et al., 7 forthcoming). The comparison focused on the consequences for estimates of willingness to pay, as 8 this is typically the focus in environmental economics. Our analysis revealed significant differences 9 in the estimates of WTP between the two methods. Specifically, for all forest attributes, mean WTP 10 was much higher when obtained using GWMNL. We also found some important structural 11 differences - several land cover variables appeared to have a reversed effect on WTP when the 12 models are compared.

13 We note that both methods have shortcomings. MXL assumes that random parameters are drawn

14 from spatially independent distributions and relies heavily on distributional assumptions. Any 15 spatial correlations that are observed are obtained from posterior Bayesian means, and they are, 16 obviously, conditional on these assumptions. On the other hand, GWMNL ignores other (non17 spatial) sources of preference heterogeneity, such as variations in income, which other research 18 has shown to matter. This shortcoming of the GWMNL model could be addressed by using a more 19 complicated weighting function which accounts for socio-demographic characteristics. However, 20 this may require the use of multiple bandwidth parameters. We tried to incorporate heterogeneity 21 with respect to socio-demographic characteristics by using a second bandwidth parameter, but the 22 results were not satisfactory, particularly when using the eye-balling technique to determine the 23 optimal bandwidth value. First of all, in such a setting there was no unique 'lower' bandwidth for 24 which our criterion was fulfilled, e.g. in case of having criterion of all WTP being below 100 EUR, 25 there could exist several pairs of bandwidths for which all WTP values are below this chosen level, 26 such that an increase in any of bandwidths would lead to exceeding this level. Researchers would 27 therefore need some additional criterion to choose the preferred model. Second, the number of 28 models that one needs to estimate increases very quickly with the number of bandwidth 29 parameters, e.g. if for a single bandwidth researcher wants to evaluate 20 different models, then 
1 for two bandwidth parameters about 20×20=400 models need to be evaluated. Another possibility

2 is to include unobserved heterogeneity in local models via estimation of latent class models instead

3 of simple multinomial logits. Such approach was used by Koster and Koster (2015) (although not in

4 the spatial context) and may be a preferable approach to GWMNL. This also introduces additional

5 computational burdens, however.

6 In light of the above, it is difficult to conclude that either of the two methods presented here for

7 the spatial modelling of willingness to pay is superior. Additional analysis of the reliability of

8 Bayesian posterior means and their vulnerability to MXL assumptions is needed. To some extent,

9 Hess (2010) approach this issue, but with no focus on welfare measures. Moreover, methods for

10 choosing an appropriate bandwidth parameter in geographically weighted discrete choice models

11 are currently under-developed. Many of the methods proposed are unsatisfactory and lead to poor

12 results. This is especially important for more advanced kernels and with multiple bandwidth

13 parameters, which would allow for spatial sources of heterogeneity. Lastly, more research on

14 sampling design for such spatial models is needed, in terms of the implications for estimates of

15 spatial relationships. We could expect that more homogenous geographic sampling would provide

16 better results, although then the sample will no longer be representative. 
Baerenklau, K. A., González-Cabán, A., Paez, C., and Chavez, E., 2010. Spatial allocation of forest recreation value. Journal of Forest Economics, 16(2):113-126.

Bateman, I. J., Day, B. H., Georgiou, S., and Lake, I., 2006. The aggregation of environmental benefit values: Welfare measures, distance decay and total WTP. Ecological Economics, 60(2):450-460.

Ben-Akiva, M., and Lerman, S. R., 1985. Discrete Choice Analysis: Theory and Application to Travel Demand. MIT Press, Cambridge, MA.

Bliemer, M. C. J., Rose, J. M., and Hess, S., 2008. Approximation of Bayesian Efficiency in Experimental Choice Designs. Journal of Choice Modelling, 1(1):98-127.

Börjesson, M., Fosgerau, M., and Algers, S., 2012. Catching the tail: Empirical identification of the distribution of the value of travel time. Transportation Research Part A: Policy and Practice, 46(2):378-391.

Brunsdon, C., Fotheringham, A. S., and Charlton, M., 1999. Some notes on parametric significance tests for geographically weighted regression. Journal of Regional Science, 39(3):497-524.

Campbell, D., Hutchinson, W. G., and Scarpa, R., 2009. Using Choice Experiments to Explore the Spatial Distribution of Willingness to Pay for Rural Landscape Improvements. Environment and planning A, 41(1):97-111.

Cho, S.-H., Poudyal, N. C., and Roberts, R. K., 2008. Spatial analysis of the amenity value of green open space. Ecological Economics, 66(2):403-416.

Cleveland, W. S., 1979. Robust locally weighted regression and smoothing scatterplots. Journal of the American Statistical Association, 74(368):829-836.

Czajkowski, M., Bartczak, A., Giergiczny, M., Navrud, S., and Żylicz, T., 2014. Providing Preference-Based Support for Forest Ecosystem Service Management. Forest Policy and Economics, 39:1-12.

Czajkowski, M., Budziński, W., Campbell, D., Giergiczny, M., and Hanley, N., forthcoming. Spatial heterogeneity of willingness to pay for forest management. Environmental and Resource Economics.

Czajkowski, M., Giergiczny, M., and Greene, W. H., 2014. Learning and fatigue effects revisited. Investigating the effects of accounting for unobservable preference and scale heterogeneity. Land Economics, 90(2):323-350.

Dekker, T., Koster, P., and Brouwer, R., 2014. Changing with the Tide: Semiparametric Estimation of Preference Dynamics. Land Economics, 90(4):717-745.

Fan, J., Farmen, M., and Gijbels, I., 1998. Local maximum likelihood estimation and inference. Journal of the Royal Statistical Society: Series B (Statistical Methodology), 60(3):591-608.

Fan, J., and Gijbels, I., 1996. Local polynomial modelling and its applications: monographs on statistics and applied probability 66. CRC Press.

Fan, J., Heckman, N. E., and Wand, M. P., 1995. Local polynomial kernel regression for generalized linear models and quasi-likelihood functions. Journal of the American Statistical Association, 90(429):141-150.

Ferrini, S., and Scarpa, R., 2007. Designs with a priori information for nonmarket valuation with choice experiments: A Monte Carlo study. Journal of Environmental Economics and Management, 53(3):342-363.

Fosgerau, M., 2007. Using nonparametrics to specify a model to measure the value of travel time. Transportation Research Part A: Policy and Practice, 41(9):842-856.

Fotheringham, A. S., Brunsdon, C., and Charlton, M., 2003. Geographically weighted regression: the analysis of spatially varying relationships. John Wiley \& Sons. 
Fotheringham, A. S., Charlton, M. E., and Brunsdon, C., 2001. Spatial variations in school performance: a local analysis using geographically weighted regression. Geographical and Environmental Modelling, 5(1):43-66.

Fotheringham, S., Charlton, M., and Brunsdon, C., 1998. Geographically weighted regression: a natural evolution of the expansion method for spatial data analysis. Environment and planning $A$, 30(11):1905-1927.

Hess, S., 2010. Conditional parameter estimates from Mixed Logit models: distributional assumptions and a free software tool. Journal of Choice Modelling, 3(2):134-152.

Hjorth, K., and Fosgerau, M., 2012. Using prospect theory to investigate the low marginal value of travel time for small time changes. Transportation Research Part B: Methodological, 46(8):917-932.

Jørgensen, S. L., Olsen, S. B., Ladenburg, J., Martinsen, L., Svenningsen, S. R., and Hasler, B., 2013. Spatially induced disparities in users' and non-users' WTP for water quality improvements-Testing the effect of multiple substitutes and distance decay. Ecological Economics, 92(0):58-66.

Koster, P. R., and Koster, H. R. A., 2015. Commuters' preferences for fast and reliable travel: A semiparametric estimation approach. Transportation Research Part B: Methodological, 81, Part 1:289301.

LeSage, J. P., 1999. A spatial econometric examination of China's economic growth. Geographic Information Sciences, 5(2):143-153.

Luo, J., and Kanala, N. K., Year. Modeling urban growth with geographically weighted multinomial logistic regression. Geoinformatics 2008 and Joint conference on GIS and Built Environment: The Built Environment and its Dynamics, International Society for Optics and Photonics, 71440M-71440M71411.

Munro, A., and Hanley, N., 1999. Information, Uncertainty and Contingent Valuation. In: Contingent Valuation of Environmental Preferences: Assessing Theory and Practice in the USA, Europe, and Developing Countries, I. J. Bateman and K. G. Willis, eds., Oxford University Press.

Nielsen, A. B., Olsen, S. B., and Lundhede, T., 2007. An Economic Valuation of the Recreational Benefits Associated with Nature-Based Forest Management Practices. Landscape and Urban Planning, 80:63-71.

Páez, A., Uchida, T., and Miyamoto, K., 2002. A general framework for estimation and inference of geographically weighted regression models: 1 . Location-specific kernel bandwidths and a test for locational heterogeneity. Environment and planning A, 34(4):733-754.

Pagan, A., and Ullah, A., 1999. Nonparametric econometrics. Cambridge university press.

Sándor, Z., and Wedel, M., 2001. Designing conjoint choice experiments using managers' prior beliefs. Journal of Marketing Research, 38(4):430-444.

Saphores, J.-D., and Li, W., 2012. Estimating the value of urban green areas: A hedonic pricing analysis of the single family housing market in Los Angeles, CA. Landscape and Urban Planning, 104(3):373387.

Scarpa, R., and Rose, J. M., 2008. Design Efficiency for Non-Market Valuation with Choice Modelling: How to Measure it, What to Report and Why. Australian Journal of Agricultural and Resource Economics, 52(3):253-282.

Timmins, C., and Murdock, J., 2007. A revealed preference approach to the measurement of congestion in travel cost models. Journal of Environmental Economics and Management, 53(2):230-249.

Timmins, C., and Schlenker, W., 2009. Reduced-Form Versus Structural Modeling in Environmental and Resource Economics. Annual Review of Resource Economics, 1(1):351-380.

Train, K., and Weeks, M., 2005. Discrete Choice Models in Preference Space and Willingness-to-Pay Space. In: Applications of Simulation Methods in Environmental and Resource Economics, R. Scarpa and A. Alberini, eds., Springer Netherlands, 1-16.

Wahba, G., 1990. Spline models for observational data. Siam. 
1 Wang, Y., Kockelman, K., and Wang, X., 2011. Anticipation of land use change through use of 2 geographically weighted regression models for discrete response. Transportation Research 3 Record: Journal of the Transportation Research Board, (2245):111-123. 


\section{$1 \quad$ Appendix $\mathrm{A}$}

2 In this section we check robustness of our results by analyzing differences in estimates for 3

3 different values of bandwidth parameter: $0.275,0.475$ and 0.6 . 0.475 is a value used throughout

4 the paper, 0.275 is the lowest bandwidth value for which all WTP except SQ are below 100 EUR

5 and 0.6 is the highest value we considered (as it is generally recommended to use lowest

6 bandwidth value which fulfill chosen criteria). In Table A1. we provide characteristics of WTP for

7 these values of bandwidth analogously as it was done in Table 2. We note that mean WTP are quite

8 robust with respect to choice of a bandwidth. Although mean estimates for bandwidth values of

90.275 and 0.6 lie more than two standard errors from estimates for bandwidth $=0.475$, they are

10 fairly close to each other. Dispersion of WTP change significantly between different bandwidth

11 values. To investigate how change in dispersion influence our results we conducted a graphical

12 analysis presented in Figure A1. In every panel we plotted parameters estimates for chosen

13 bandwidth values: 0.275 (blue lines), 0.475 (red lines) and 0.6 (yellow lines) with their 95\%

14 confidence intervals (dotted lines) against longitude. We see that, indeed increased dispersion for

15 bandwidth of 0.275 leads to several 'peaks', with very wide confidence intervals, for every

16 parameter. Because of that for lower bandwidth value many WTP estimates in local models

17 occurred insignificant. Estimates for 0.6 bandwidth usually lies within confidence interval for

18 estimates for bandwidth of 0.475 . We therefore conclude that choosing bandwidth of 0.475 is

19 justified as it allows to avoid implausible 'peaks' in WTP (especially for SQ) and insignificant

20 estimates. We also do not see any reason to choose bandwidth above 0.475 as the plots does not

21 reveal any particular under-smoothing when comparing lines for bandwidth of 0.475 with lines for

22 bandwidth of 0.6 . 
1 Table A1. Characteristics of distributions of estimated WTP from GWMNL model for different

2 bandwidth values (stanrard errors in [] brackets, coefficients in WTP-space, in EUR per year)

\begin{tabular}{|c|c|c|c|c|c|c|}
\hline & \multicolumn{2}{|c|}{ Bandwidth $=0.275$} & \multicolumn{2}{|c|}{ Bandwidth $=0.475$} & \multicolumn{2}{|c|}{ Bandwidth $=0.6$} \\
\hline & Mean & Std. Dev. & Mean & Std. Dev. & Mean & Std. Dev. \\
\hline$N A T_{1}$ & $16.4541^{* * *}$ & $10.9360 * * *$ & $15.7107^{* * *}$ & $6.8786 * * *$ & $15.5389 * * *$ & $5.7223 * * *$ \\
\hline $\begin{array}{l}\text { (passive protection of most valuable } \\
\text { forests - substantial improvement) }\end{array}$ & [0.2225] & [0.5033] & [0.1258] & [0.1701] & [0.0968] & [0.1138] \\
\hline$N A T_{2}$ & $24.0868 * * *$ & $15.4706 * * *$ & $23.0767 * * *$ & $10.0173 * * *$ & $22.7602 * * *$ & $8.1253 * * *$ \\
\hline $\begin{array}{l}\text { (passive protection of most valuable } \\
\text { forests - partial improvement) }\end{array}$ & [0.3136] & {$[0.5758]$} & {$[0.1826]$} & {$[0.2575]$} & [0.1390] & [0.1682] \\
\hline$T R A_{1}$ & $29.6563 * * *$ & $16.7661^{* * *}$ & $28.3018^{* * *}$ & $11.0293^{* * *}$ & $27.8463^{* * *}$ & $9.0786 * * *$ \\
\hline $\begin{array}{l}\text { (the amount of litter in forests - } \\
\text { partial improvement) }\end{array}$ & [0.3318] & {$[0.4383]$} & {$[0.2001]$} & {$[0.2316]$} & [0.1530] & {$[0.1704]$} \\
\hline$T R A_{2}$ & $39.8062 * * *$ & $22.7725^{* * *}$ & $37.8590 * * *$ & $14.7594 * * *$ & $37.1348 * * *$ & $11.8575^{* * *}$ \\
\hline $\begin{array}{l}\text { (the amount of litter in forests - } \\
\text { substantial improvement) }\end{array}$ & {$[0.4591]$} & [0.6970] & {$[0.2721]$} & [0.3624] & {$[0.2041]$} & {$[0.2446]$} \\
\hline$I N F_{1}$ & $12.9375^{* * *}$ & $7.5310^{* * *}$ & $12.7121^{* * *}$ & $5.1219 * * *$ & $12.6410^{* * *}$ & $4.3811^{* * *}$ \\
\hline $\begin{array}{l}\text { (tourist infrastructure }- \text { partial } \\
\text { improvement) }\end{array}$ & [0.1469] & [0.1862] & [0.0915] & [0.1003] & {$[0.0736]$} & [0.0793] \\
\hline$I N F_{2}$ & $21.1835^{* * *}$ & $11.5530^{* * *}$ & $20.6085^{* * *}$ & $8.2931^{* * *}$ & $20.4056 * * *$ & $7.1172 * * *$ \\
\hline $\begin{array}{l}\text { (tourist infrastructure - substantial } \\
\text { improvement) }\end{array}$ & [0.2223] & [0.2611] & [0.1388] & [0.1543] & {$[0.1064]$} & [0.1127] \\
\hline$S Q$ & $38.7161 * * *$ & $37.5901 * * *$ & $39.3765 * * *$ & $26.2943 * * *$ & $39.5860 * * *$ & $23.3231^{* * *}$ \\
\hline $\begin{array}{l}\text { (alternative specific constant for the } \\
\text { no-choice alternative) }\end{array}$ & [0.6308] & [1.1447] & [0.3866] & {$[0.4566]$} & [0.3046] & [0.3690] \\
\hline $\cos T$ & $0.0626 * * *$ & $0.0403 * * *$ & $0.0575 * * *$ & $0.0240 * * *$ & $0.0561 * * *$ & $0.0182 * * *$ \\
\hline (annual cost - tax increase) & {$[0.0005]$} & {$[0.0008]$} & {$[0.0004]$} & {$[0.0005]$} & {$[0.0003]$} & {$[0.0003]$} \\
\hline
\end{tabular}

4

5

6 
Figure A1. Parameters values with different bandwidths values plotted against longitude
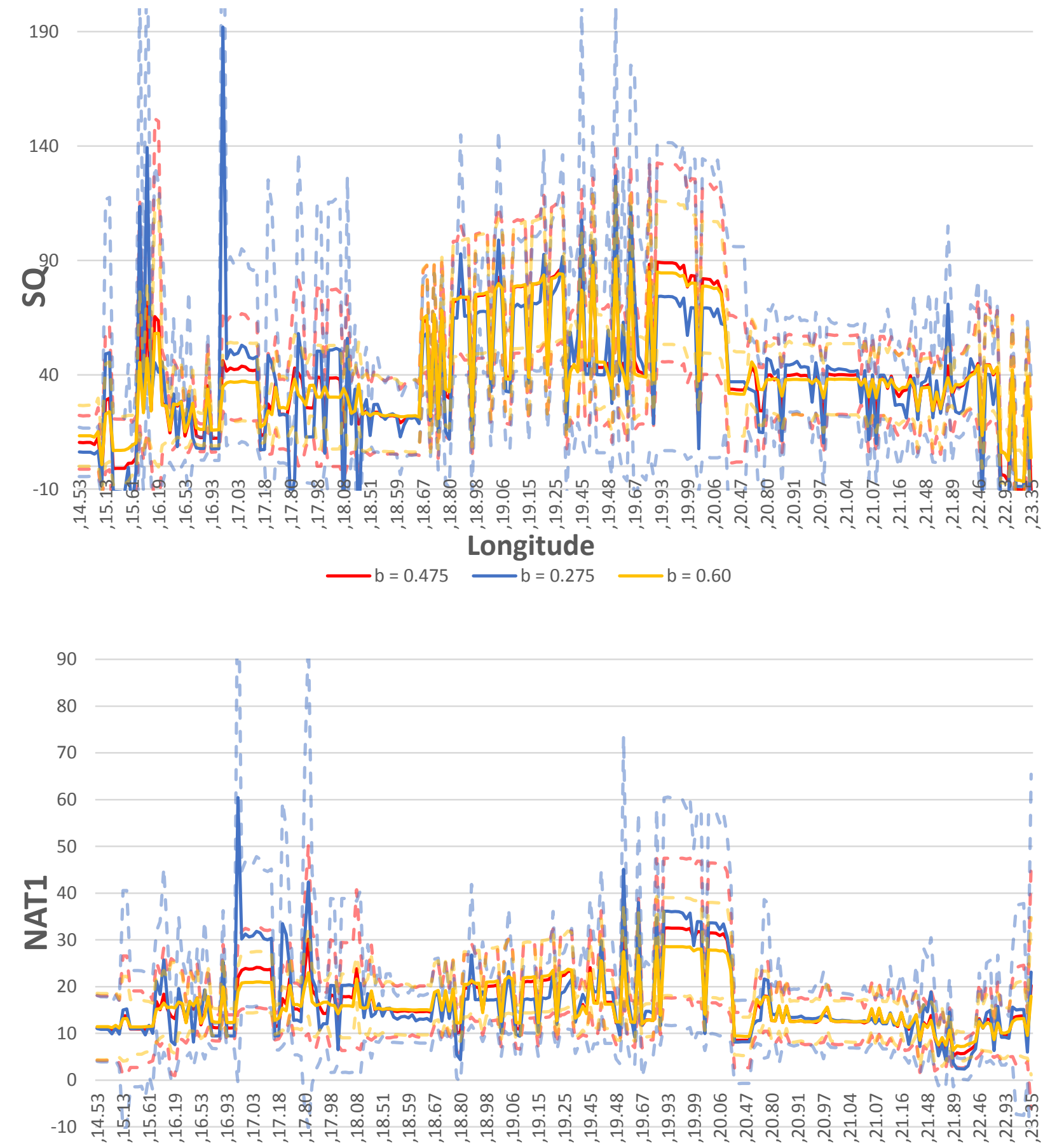

\section{Longitude}

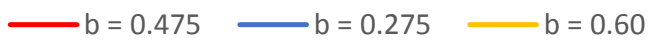




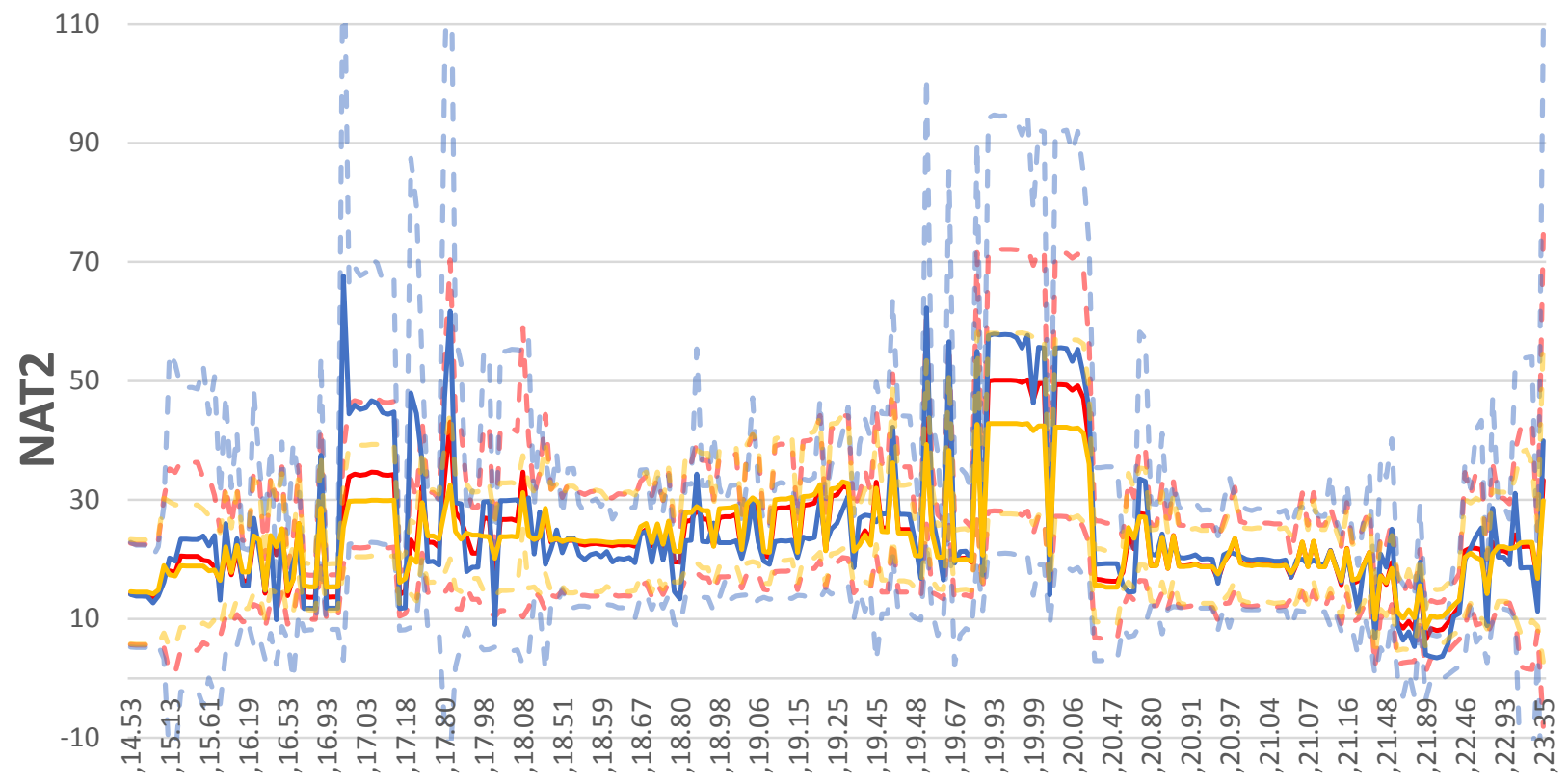

Longitude
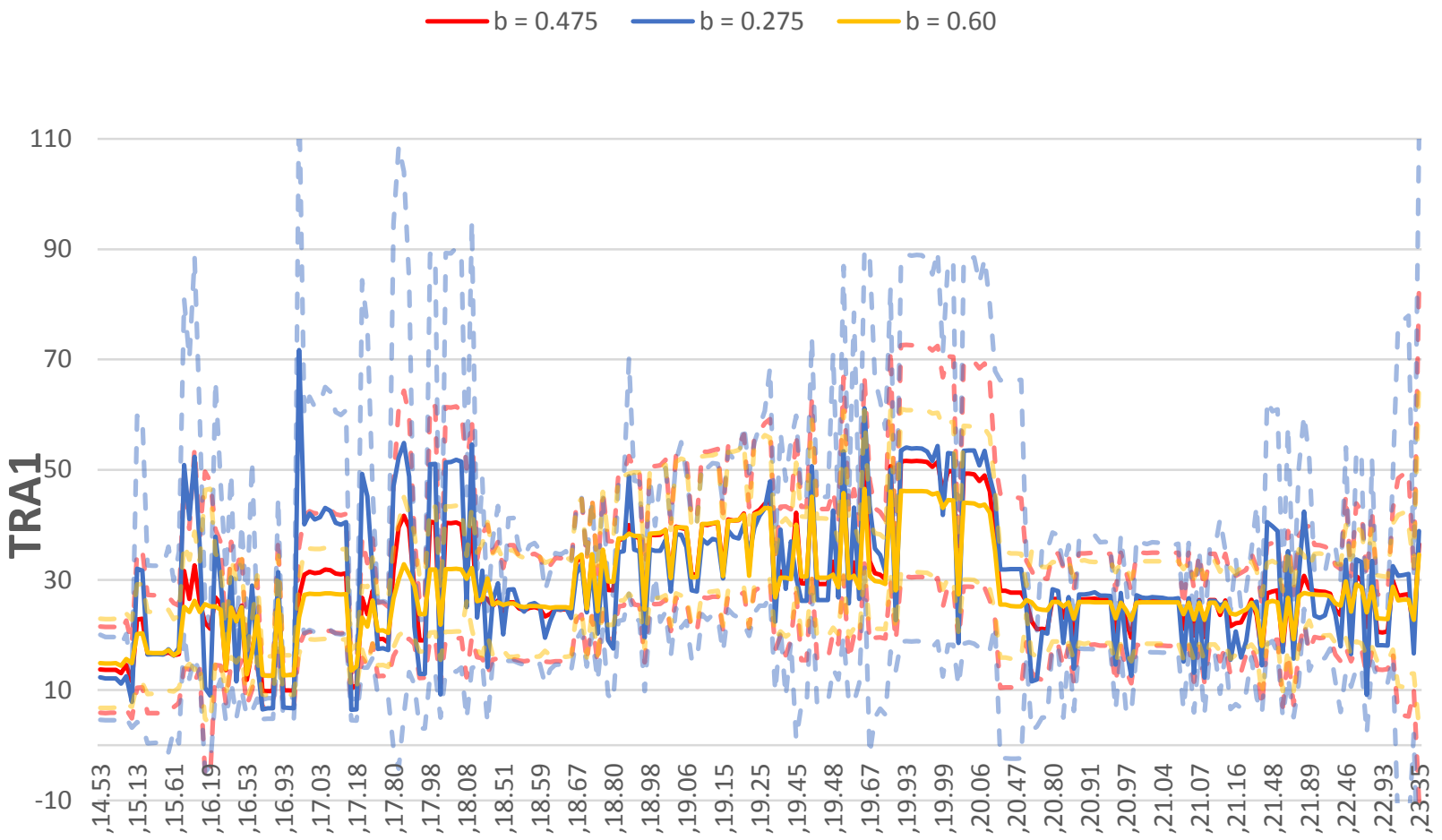

Longitude

$\longrightarrow b=0.475-b=0.275-b=0.60$ 


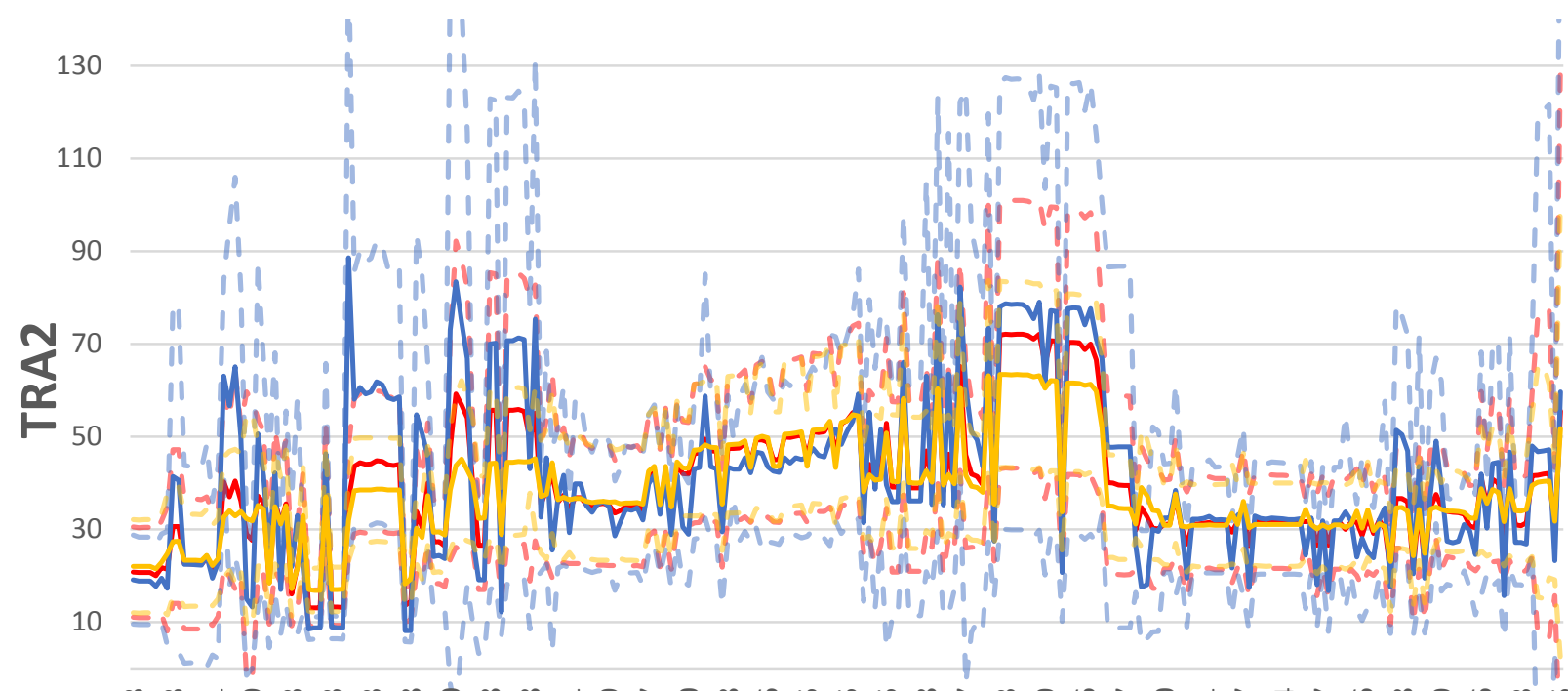

-10 ஸึ

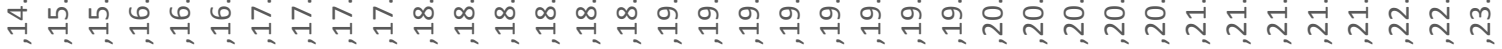

\section{Longitude}
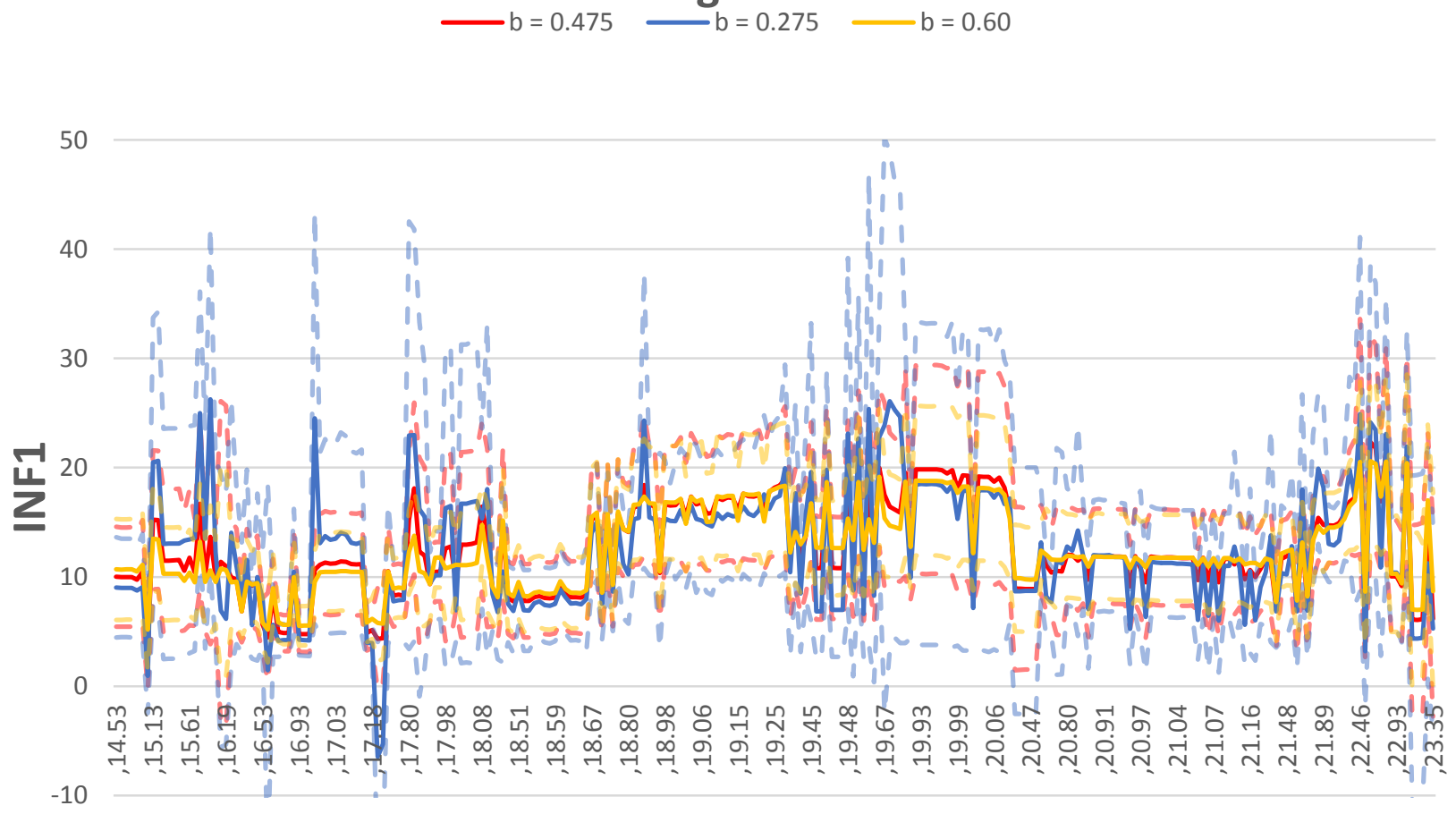

Longitude

$\longrightarrow b=0.475-b=0.275-b=0.60$ 


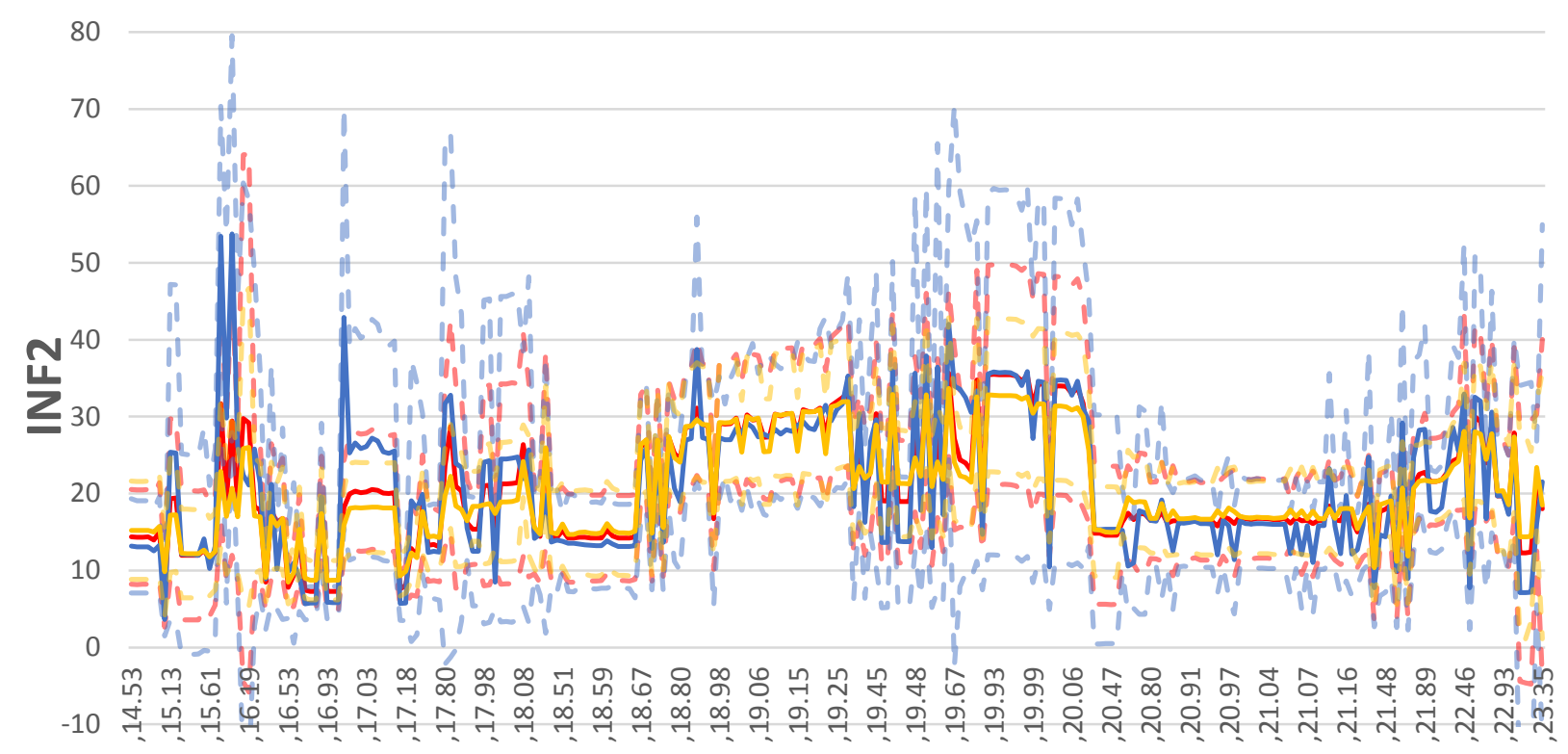

Longitude
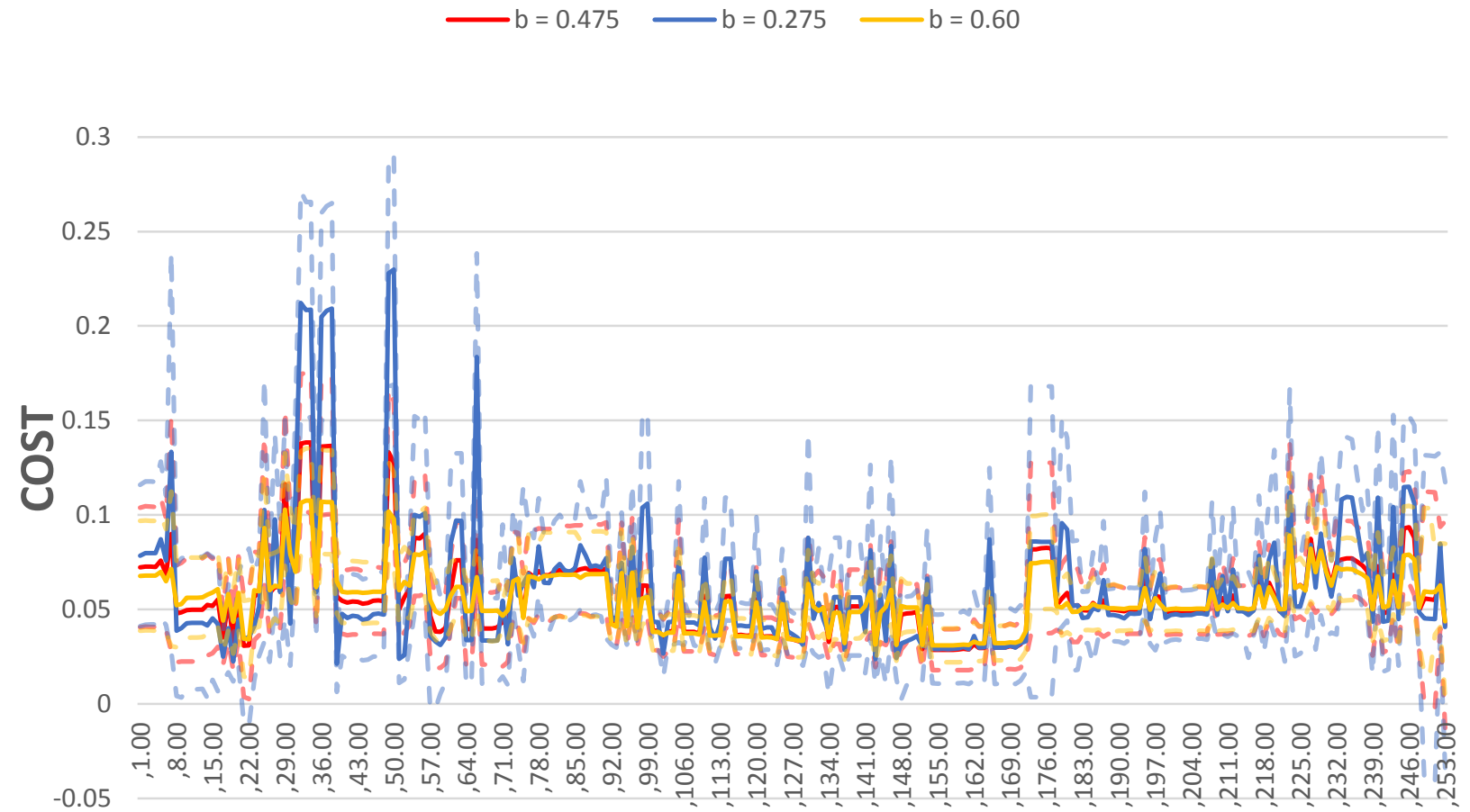

\section{Longitude}

$\longrightarrow b=0.475-b=0.275-b=0.60$ 
Appendix B. Results of regressions where the dependent variables are the absolute values of differences between WTP from GWMNL and location-specific MXL.

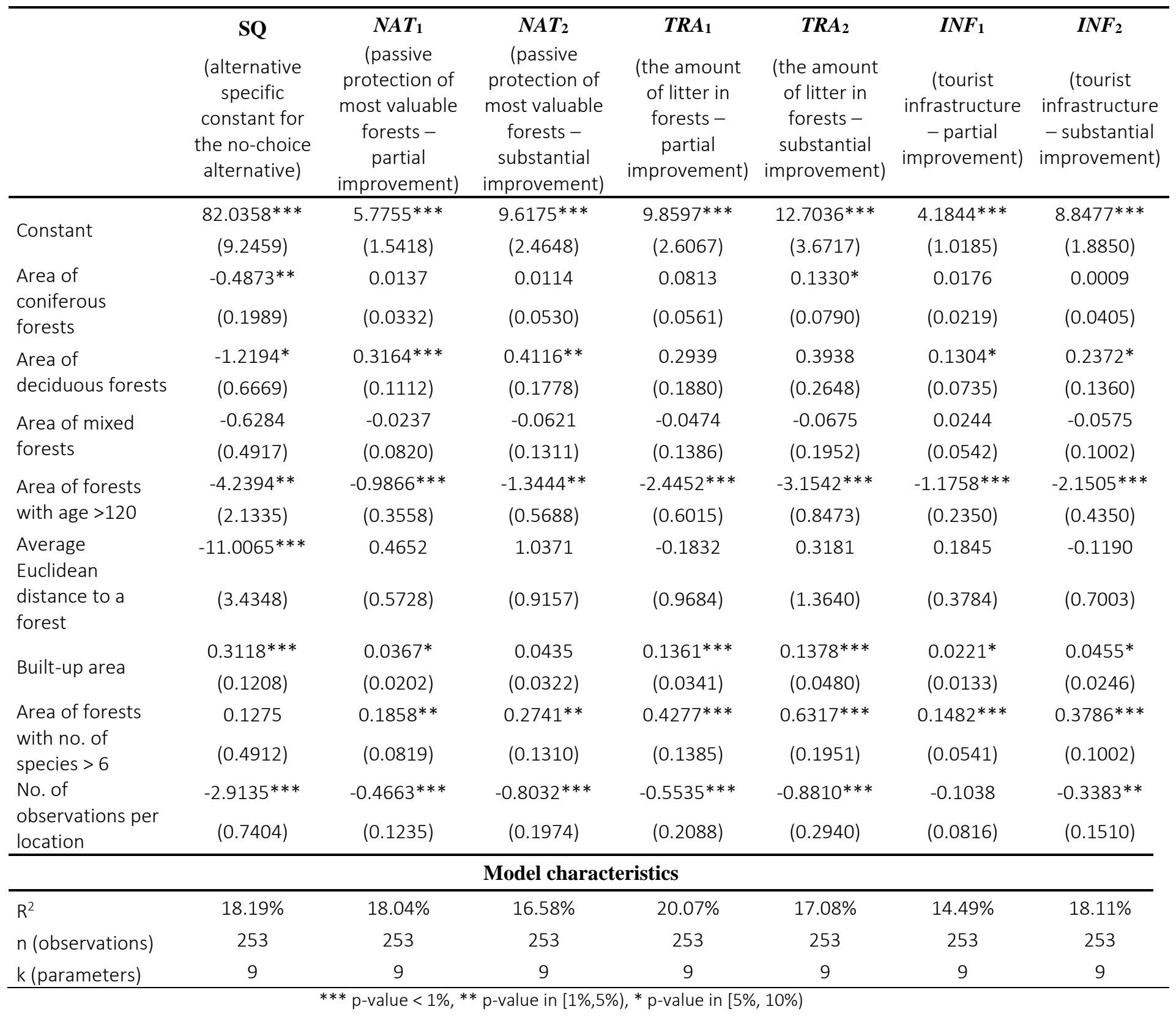

